Asociación de Jóvenes Historiadores y Arqueólogos de Murcia

PANTR REL

REVISTA DE CIENCIA

$$
\begin{array}{r}
Y \\
\text { DIDÁCTICA } \\
\text { DE LA HISTORIA } \\
\text { III - } 2^{2} \text { época }
\end{array}
$$




\section{ASOCIACIÓN DE JÓVENES HISTORIADORES Y ARQUEÓLOGOS DE MURCIA}

\section{PANTA REI. REVISTA DE CIENCIA Y DIDÁCTICA \\ DE LA HISTORIA III. $2^{a}$ época}


CONSEJO EDITORIAL: LAURA ARIAS FERRER

ALEJANDRO EGEA VIVANCOS

ANTONINO GONZÁLEZ BLANCO

RAFAEL GONZÁLEZ FERNÁNDEZ

JOAQUÍN LOMBA MAURANDI

ENRIQUE QUINTANA CIFUENTES

GONZALO MATILLA SÉIQUER

JOSÉ ANTONIO MOLINA GÓMEZ

REDACTOR JEFE:

ÁNGEL LUIS GONZÁLEZ TORRES

Depósito legal: MU-966-1995

I.S.S.N. 1136-2464

Edición de Compobell, S.L. Murcia 


\section{ÍNDICE}

AGRADECIMIENTOS

Presentación

Por Alejandro Egea Vivancos, Laura Arias Ferrer

\section{ARTÍCULOS}

Análisis microscópico de la industria lítica: la traceología

Por Ignacio Martín Lerma

Reflexiones en torno al estudio de la economía en Prehistoria

Por Valentín Martínez García

Aplicaciones SIG en el análisis de las sociedades del pasado. Un caso de estudio: Las primeras comunidades campesinas del Levante Peninsular

Por Gabriel García Atiénzar

La situación actual de los estudios de egiptología en España

Por José Javier Martínez García

La vida cotidiana en el Imperio Asirio. Usos y costumbres de un pueblo que conquistó las Cuatro Regiones del Mundo

Por Ángel Luis González Torres

Las formas de intercambio y las estructuras comerciales orientalizantes en la Vega Baja del Segura: dos variables de estudio arqueológico

Por Sara Pernas García 
Evolución de los patrones de asentamiento en época ibérica. Una propuesta de estudio del mundo ibérico murciano a través del análisis del poblamiento

Hispania Tierra de Roma. Organización y gestión del suelo

Por $M^{a}$ Carmen Santapau Pastor

Hacia una arqueología de la España bizantina. Breves notas a propósito del seminario Work in progress

Por Jaime Vizcaíno Sánchez

Reflexiones acerca de un estudio sobre las estancias auxiliares en la arquitectura barroca catedralicia

Por Francisca del Baño Martínez

La investigación sobre fisiognomía y expresión de las pasiones. Objetivos y metodología

Por María del Mar Albero Muñoz 


\title{
EVOLUCIÓN DE LOS PATRONES DE ASENTAMIENTO EN ÉPOCA IBÉRICA. UNA PROPUESTA DE ESTUDIO DEL MUNDO IBÉRICO MURCIANO A TRAVÉS DEL ANÁLISIS DEL POBLAMIENTO
}

LETICIA LÓPEZ MONDÉJAR

\section{Resumen}

Como han demostrado los últimos trabajos llevados a cabo en la línea de la arqueología del paisaje, el análisis del poblamiento y, de forma particular, de los distintos criterios que definen el patrón de asentamiento de los núcleos ibéricos ofrece nuevas perspectivas de aproximación a esta cultura. En éstas, los Sistemas de Información Geográfica constituirán una herramienta fundamental para abordar el análisis de muchos de esos aspectos. Además, este nuevo enfoque, desarrollado ya en otros ámbitos peninsulares, y que permite llevar a cabo un estudio global y diacrónico de dichos asentamientos, se revela aun de mayor interés en el ámbito regional murciano, donde apenas si contamos con estudios en esta línea.

Palabras clave: Mundo ibérico, paisajes, patrón de asentamiento, territorio, Sistemas de Información Geográfica.

\begin{abstract}
The recent works in line with the landscape's archaeology have showed the utility and the importance of the Iberian settlement pattern and offer news perspectives to approach the Iberian culture. In connection with this, the Geographical Information Systems constitute an essential tool to analyzer many of these aspects. This new approach, developed already in other peninsular areas, allows, in the Iberian
\end{abstract}


Southest, a diachronic and global study of the Iberian age. Furthermore, it presents the greatest interest in Murcia, where scarce studies are found in this line.

Key words: Iberian age, landscape, settlement patterns, territory, Geographic Information Systems.

\section{Introducción}

El estudio del poblamiento y de los patrones de asentamiento en época ibérica ha constituido, en los últimos años, una interesante línea de investigación, ofreciendo importantes datos relativos ya no sólo a los modelos que caracterizan la propia ocupación del espacio a lo largo de este periodo, sino, también, sobre toda una amplia diversidad de aspectos que nos permiten observar, de forma global, los rasgos económicos, socio-políticos y culturales que definen el mundo ibérico peninsular.

En el presente trabajo, enmarcado en el programa de seminarios 'Work in Progress... (Jóvenes Investigando)', que se desarrolló en la Universidad de Murcia a lo largo de los años 2006-2007, intentaremos, en la línea y objetivos que caracterizaron dicha actividad, presentar brevemente los aspectos más novedosos del proyecto de investigación que estamos llevando a cabo en esta universidad. Así, a lo largo de las páginas siguientes, plantearemos los rasgos básicos de dicho proyecto, centrándonos, especialmente, en aquellos aspectos de carácter metodológico, e intentando mostrar, en general, el interés que ofrece el estudio de los patrones de asentamiento y de la ocupación del territorio en estas tierras del Sureste peninsular para comprender, no sólo el desarrollo del mundo ibérico en las mismas, sino también, el proceso de integración de este en la órbita de Roma.

Nuestro proyecto pretende, así, lograr, dejando a un lado los trabajos que, hasta el momento, se han centrado en análisis concretos de aspectos particulares del mundo ibérico regional, una visión global, comparativa y diacrónica del mismo, que nos permita encuadrarlo en el desarrollo histórico del Sureste y comprender, quizás más claramente, los cambios que supuso la llegada de la presencia romana en el modelo de ocupación y organización territorial indígena.

Tres son fundamentalmente las cuestiones que nos interesan a la hora de plantear las bases metodológicas y los objetivos que definen nuestra investigación, y será a ellas a las que atenderemos más detenidamente en las páginas siguientes.

Por un lado, abordaremos brevemente las posibilidades y complejidad que definen un estudio de este tipo y un enfoque como el que se plantea. Estas, han quedado ya de manifiesto en los múltiples trabajos que han abordado, desde esta misma perspectiva, 
el análisis del poblamiento ibérico en otras áreas peninsulares, así como también, el estudio de los patrones de asentamiento y de la ocupación y apropiación del espacio en otros ámbitos del Mediterráneo.

En segundo lugar, pretendemos encuadrar nuestro proyecto de trabajo entre aquellas investigaciones que han abordado el estudio del mundo ibérico regional, intentando además, advertir los posibles problemas que un análisis del mismo como el propuesto plantea, así como las ventajas del mismo. Sólo en base a ellas es posible justificar el objeto y el interés del mismo, así como la novedad que representa un enfoque de este tipo en el marco de los estudios ibéricos llevados a cabo, hasta ahora, en la Región.

Finalmente, será nuestro último objetivo plantear los rasgos que definen la metodología utilizada para llevar a cabo dicho estudio, teniendo muy presentes tanto las posibilidades que ofrece este como las limitaciones del mismo, así como también aquellos aspectos que condicionan y caracterizan el análisis del propio ámbito de estudio elegido, valorando, en todo momento, la utilidad de los Sistemas de Información Geográfica como herramienta fundamental para llevar a cabo dicho análisis, y siempre en conexión con las aportaciones que han ofrecido, en esta misma línea, los trabajos realizados en otras áreas peninsulares.

\section{El paisaje como elemento de análisis: una aproximación al mundo ibérico a través del estudio del poblamiento}

A lo largo de los últimos años, han sido muy numerosos los trabajos que han abordado el estudio del poblamiento y, de forma más amplia, el de los paisajes históricos, en la Península Ibérica y en otros ámbitos del Mediterráneo prerromano. El paisaje, entendido como el resultado de la acción y transformación del medio por parte de una determinada comunidad humana, se presentaría, así, como parte integrante del registro arqueológico y el mejor reflejo de las estructuras sociales, políticas, económicas, e incluso, simbólicas, de aquella ${ }^{1}$. En este sentido, el estudio del poblamiento, de los patrones de asentamiento y, en definitiva, de aquellos criterios que definen la ocupación del territorio, se convierten en elementos fundamentales de análisis, ya que encierran información sobre los más diversos aspectos referidos a esa comunidad,

1 FÁBREGA, P. Poblamiento y territorio de la Cultura Castreña en la comarca de Ortegal, CAPA (Cuadernos de Arqueoloxía e Patrimonio) 19. Santiago de Compostela, 2004, pp. 10; HAGGET, P. Análisis locacional en la Geografía Humana. Barcelona, 1976, pp. 18; CHAPA, T. et al. «Aplicación de los Sistemas de Información Geográfica a la Investigación y Gestión del Patrimonio Arqueológico en el Bajo Jarama (Madrid)», en MARTÍN DE LA CRUZ, J. C. y LUCENA MARTÍN, A. M. (Coord.): Actas del I Encuentro Internacional. Informática aplicada a la investigación y la gestión arqueológicas (Córdoba, 5-7 de mayo, 2003) I. Córdoba, 2004, pp. 154. 
permitiendo abordar un estudio de la misma en todas sus dimensiones ${ }^{2} \mathrm{y}$, quizás lo que es aun más interesante, desde una perspectiva fundamentalmente diacrónica, que facilitaría el análisis y la comprensión de los procesos de transformación de dicho paisaje, como la que supondrá la propia romanización de ese mundo indígena ${ }^{3}$.

Desde esta perspectiva, y en el caso particular del mundo ibérico, el característico paisaje marcado por la aparición de importantes oppida que dominan y controlan amplios territorios, consolidándose como centros clave desde el punto de vista socio-político y económico, no sería así, sino el reflejo, en todo el sur peninsular, de la presencia de las aristocracias clientelares ibéricas ${ }^{4}$. Del mismo modo, por ejemplo, y para un periodo posterior, bastaría recordar la imagen que pudo ofrecer el territorio de Lorca en época medieval, dominado por castillos y torres de control, y configu-

2 VICENT, J. «Fundamentos teórico metodológicos para un programa de investigación arqueogeográfica», en LÓPEZ GARCÍA, P. (Ed.): El cambio cultural del IV al II milenios a.C. en la comarca Noroeste de Murcia vol. 1. Madrid, 1991, pp. 42-47; VICENT, J. «Entornos», Arqueología Espacial 19-20, 1998, pp. 165; MAYORAL, V. Paisajes agrarios y cambio social en Andalucía oriental entre los períodos ibérico y romano, Anejos de Archivo Español de Arqueologia XXXI. Madrid, 2004, pp. 269 y siguientes; CRIADO, F. «Visibilidad e interpretación del registro arqueológico», Trabajos de Prehistoria 50, 1993, pp. 39-56; CRIADO, F. «Introduction: Combining the different dimensions of cultural space: Is a total Archaeology of Landscape possible?», Trabajos en Arqueología del Paisaje 2. Landscape, Archaeology, Heritage, 1997, pp. 7; CHAPA et al., op. cit., 2004, pp. 154-155; GRAU, I. «La construcción del paisaje ibérico: aproximación SIG al territorio protohistórico de la Marina Alta», SAGVNTVM (P.L.A.V.) 36, 2004, pp. 72-73; FÁBREGA, op. cit., 2004, pp. 10; WITCHER, R.E. «GIS and Landscapes of Perception», en GILLINGS, M., et al. (Ed.): The Archaeology of Mediterranean Landscapes 3. Geographical Information Systems and Landscape Archaeology. Oxford, 1999, pp. 17-18; MACCHI, G. «Sulla misurazione delle forme d'occupazione sociale dello spazio medievale», Archeologia Medievale XXVIII, 2001, pp. 7-21; MATTEINI, T. y MIRRI, L. «Archeologia e architettura del paesaggio. Il caso delle "logge"», en CAMBI, F. y MANACORDA, D. (a cura di): Materiali per Populonia. Quaderni del Dipartimento di Archeologia e Storia delle Arti, sezione archeologica - Università di Siena 1. Firenze, 2002, pp. 183-190; LLOBERA, M. «Exploring the topography of mind: GIS, social space and archeology», Antiquity vol. 70, n 269, september 1996, pp. 614 y 621-622; ADROHER, A. y LÓPEZ, C. «Pasado, presente y futuro de las investigaciones sobre el mundo ibérico en las altiplanicies granadinas», Revista d'Arqueologia de Ponent 11-12, 2001-2002, pp. 43-48.

3 GRAU, I. «La reorganización del territorio durante la romanización: un caso de estudio en el área central de la Contestania», en ABAD CASAL, L. (Ed.): De Iberia in Hispaniam. La adaptación de las sociedades ibéricas a los modelos romanos. (Actas del Seminario de Arqueología organizado por la Fundación Duques de Soria, del 23 al 27 de julio de 2001). Alicante, 2003, pp. 53-73; GRAU, I. «Romanization in Eastern Spain: a GIS Approach to Late Iberian Iron Age Landscape», en BERGER, J.-F., et al. (Dir.): Temps et espaces de l'homme en société, analyses et modèles spatiaux en archéologie. XXV rencontres internationales d'archéologie et d'histoire d'Antibes. Antibes, 2005, pp. 325-334; GRAU, I. «Transformaciones culturales y modelos espaciales. Aproximación SIG a los paisajes de la romanización», en GRAU MIRA, I. (Ed.): La aplicación de los SIG en la arqueología del paisaje. Alicante, 2006, pp. 211-226.

4 RUIZ, A. «La sociedad de los príncipes», Saguntum extra 3. Ibers. Agricultors, artesans i comerciants. III Reunió sobre economía en el Mòn Ibèric, 2000, pp. 307-328; GRAU, I. y MORATALLA, J. «El paisaje antiguo», en Iberia, Hispania, Spania. Una mirada desde Ilici. Alicante, 2004, pp. 111-118. 
rando un paisaje que no hará sino reflejar los rasgos que definen económica, social y políticamente este momento en dicha comarca, así como, en última instancia, la propia mentalidad y las preocupaciones que marcarían la vida de sus habitantes en esas centurias 5 .

Sin embargo, y al margen de esas posibilidades, ¿qué dificultades plantea un estudio de este tipo? En general, y al margen de los múltiples problemas de carácter particular que, como veremos más adelante, caracterizan el estudio concreto de estas tierras murcianas, así como la realización de los distintos análisis espaciales llevados a cabo, podríamos indicar una serie de aspectos, comunes a cualquier investigación en esta misma línea, que reflejan, quizás con mayor claridad, la complejidad de llevar a cabo un estudio del paisaje.

En primer lugar, cabría señalar, ante todo, la propia problemática que supone el intentar advertir e integrar en el análisis de un determinado paisaje, los distintos aspectos que lo conforman, y que, necesariamente, deben ser estudiados de forma conjunta e interrelacionada ${ }^{6}$, especialmente si tenemos presente la complejidad que supone el abordar cuestiones como pueden ser aquellas relativas al ámbito simbólico o tecnológico e, incluso, aproximarnos a aspectos como serían los propios valores culturales y las condiciones ecológicas que influirán también en la acción de una determinada comunidad sobre el medio ${ }^{7}$.

Del mismo modo, podríamos destacar, además, la dificultad de analizar paisajes y sociedades, con un claro carácter dinámico, en constante cambio, ya no sólo por su propia dinámica interna, sino también como consecuencia de los múltiples influjos externos, púnicos, griegos y romanos, que dejarán también su huella en dichas comunidades indígenas y, en definitiva, en ese paisaje ${ }^{8}$.

Finalmente, el propio hecho de que este último constituya un elemento, ya no sólo en constante transformación sino, más bien, 'en continua construcción', hace en ocasiones complicado advertir las huellas de la acción de determinados procesos, tal vez destruidas a lo largo de las centurias siguientes ${ }^{9}$.

Al margen de dichas dificultades, las amplias posibilidades que ofrece el análisis de los paisajes y de los distintos elementos que los constituyen, favorecido además

5 CRIADO, op. cit., 1997, pp. 8.

6 MATTEINI y MIRRI, op. cit., 2002, pp. 183-190.

7 VICENT, op. cit, 1991, pp. 44-47; ADROHER y LÓPEZ, op. cit., 2001-2002, pp. 46; CRIADO, op. cit., 1997, pp. 5; MACCHI, op. cit, 2001, pp. 11.

8 MATTEINI y MIRRI, op. cit., 2002, pp. 183-190; CHAPA et al., op. cit., 2004, pp. 155; FOWLER, P.J. «Site, landscape and context», en FRANCOVICH, R. y MANACORDA, D. (a cura di): Lo scavo archeologico: dalla diagnosi all'edizione. III Ciclo di Lezioni sulla Ricerca applicata in Archeologia. Certosa di Pontignano (Siena), 6-18 novembre 1989. Firenze, 1990, pp. 127-129.

9 VICENT, op. cit., 1991, pp. 44-47; MATTEINI y MIRRI, op. cit., 2002, pp. 183-190; MACCHI, op. cit., 2001, pp. 8. 
por las ventajas que para un estudio diacrónico ofrecen, como apuntábamos, los Sistemas de Información Geográfica, ha hecho de esta línea de investigación, en los últimos años, uno de los principales enfoques de trabajo para abordar el estudio del mundo ibérico y, muy especialmente, de su transformación con la llegada e instalación de Roma en la Península Ibérica.

En este sentido, es precisamente el análisis del poblamiento, de los patrones de asentamiento y de la propia ocupación y articulación del territorio, uno de los aspectos que más interés ha despertado entre los trabajos llevados a cabo, dentro de ese mismo marco cronológico, las vecinas tierras levantinas y andaluzas ${ }^{10}$, en las que ha permitido comprender la progresiva evolución de ese mundo indígena, mostrando los criterios que definirían, en cada caso, dicho proceso de integración, y analizando las transformaciones que implicaría la presencia romana en estos ámbitos del sur y el Levante peninsular. Dichos estudios, han logrado así, ofrecer un excelente panorama de los paisajes ibéricos y de los procesos que conformaron aquellos de época romana, que constituye, sin duda alguna, un valioso punto de partida para el proyecto que pretendemos llevar a cabo en el área murciana.

Tal y como hemos indicado anteriormente, el estudio global de los diferentes paisajes históricos incluye, a su vez, el estudio de la propia sociedad que los crea y los transforma, de la explotación del medio, de las estrategias organizativas de un determinado territorio, de los valores simbólicos y culturales de una comunidad y, en definitiva, de los más diversos aspectos que conforman esas sociedades. Desde este punto de vista, todos estos factores, económicos, políticos, sociales y culturales, se hallan totalmente conectados y entrarían dentro de aquella dimensión del paisaje que podríamos definir como 'paisaje social', siendo precisamente en ella en la que entra en juego el estudio del poblamiento y de los patrones de asentamiento del mundo ibérico. A pesar de ello, también las dimensiones ambiental y simbólica de dicho

10 ADROHER y LÓPEZ, op. cit., 2004; ABAD, L. «Entre Iberia y Roma. Transformaciones urbanísticas y reorganización territorial», en Territoris Antics a la Mediterrània i a la Cossetània oriental. Actes del Simposi Internacional d'Arqueologia del Baix Penedès. El Vendrell, del 8 al 10 de novembre de 2001. Barcelona, 2003, pp. 117-127; GRAU, I., op. cit., 2003, pp. 53-73, op. cit., 2004, pp. 61-75 y op. cit., 2006, pp. 211-226; MORATALLA, J. «El territorio meridional de la Contestania», en Jornadas de Arqueología 'La Contestania Ibérica, treinta años después'. Alicante, 2005, pp. 91-118; RUIZ, A., MOLINOS, M. y RÍSQUEZ, C., «Peuplement et territoire à l’Âge du Fer ancien au Sud de la Péninsule ibérique», en JANIN, T. (Ed.): Mailhac et le Premier Âge du Fer en Europe occidentale. Hommages à Odette et Jean Taffanel. Actes du Colloque international de Carcassonne, 17-20 septembre 1997. Monographies d'Archéologie Méditerranéenne 7. 2000, pp. 53-60; BONET, H. y MATA, C. «Organización del territorio y poblamiento en el País Valenciano entre los siglos VII al II a.C.» en BERROCAL-RANGEL, L. y GARDES, P. (Coord.): Entre celtas e íberos. Las poblaciones protohistóricas de las Galias e Hispania. Madrid, 2001, pp. 175-186; MARTÍNEZ, C. y MUÑOZ, F.A. Poblamiento Ibérico y Romano en el sureste peninsular: la Comarca de los Vélez. (Almería). Granada, 1999. 
paisaje, deberán ser también tenidas en cuenta para lograr una visión de conjunto de ese mundo indígena y para comprender aquellos criterios que definirían la ocupación del territorio, las estrategias de explotación del mismo y la decisión locacional de muchos de esos centros comarcales analizados ${ }^{11}$.

Si bien son muy diversos elementos que formarían parte de ese 'paisaje social', tales como lugares de hábitat, espacios funerarios, santuarios y lugares de culto, vías de comunicación y áreas de producción, entre otros, hemos considerado de mayor interés, partiendo de las limitaciones que imponen el propio territorio y los periodos de estudio, abordar de forma especial el análisis del poblamiento. Este, entendido en sentido amplio, y no únicamente reducido al mero espacio de hábitat, puede ofrecernos interesante información sobre múltiples aspectos, y especialmente, sobre aquellos rasgos económicos y socio-políticos que definirían el mundo indígena de estas tierras.

El poblamiento, si bien no es el único, sí constituye uno de los principales aspectos para el estudio del paisaje ibérico, y el que, en última instancia, daría también una cierta cohesión a todos los demás elementos que formarían parte del mismo. Así, partimos de la idea de que, los asentamientos, en tanto que ámbitos en los que se conjugan y entrelazan aspectos sociales, económicos, culturales y espirituales de la comunidad, constituyen un aspecto fundamental a la hora de comprender los rasgos que definen los modelos de ocupación y organización territorial y, en última instancia, la evolución de los mismos y la configuración y transformación de esos paisajes históricos.

No olvidemos, en este sentido, que se ha llegado a definir los asentamientos como una combinación de 'compromiso y equilibrio' entre variables ecológicas, estructuras sociales, condicionamientos culturales, etc., indicando incluso que constituirían una mediación entre 'psiche' y espacio ${ }^{12}$. Desde este punto de vista, el análisis del poblamiento y de los patrones de asentamiento, así como de su evolución, nos permitirá, quizás, aproximarnos también a esos otros aspectos del paisaje que, en cierta medida, articularían también dicho poblamiento, y en relación a los cuales, sin embargo, dispondríamos de una información mucho más limitada ${ }^{13}$.

El estudio de esos asentamientos, de su patrón de asentamiento y, por tanto, de aquellos criterios que definirían la ocupación del espacio, en este caso, en las comarcas murcianas de Lorca y el Noroeste, en las que pretendemos centrar nuestra

11 HARVEY, D. «Verso una filosofia dello spazio sociale», en VAGAGGINI, V. (a cura di): Spazio Geografico e Spazio Sociale. Milano, 1978, pp. 83-84; CRIADO, op. cit., 1997, pp. 7-8.

12 MACCHI, op. cit., 2001, pp. 11-12.

13 SANTOS VELASCO, J.A. Cambios sociales y culturales en época ibérica: el caso del Sureste. Madrid, 1994, pp. 13-15. 
investigación, nos permitirá aproximarnos, así, a aspectos como los posibles modelos que caracterizan dicho patrón en cada momento, las posibles tipologías y jerarquías de centros que se observan en cada periodo, aquellos núcleos de carácter principal y el modo en el que articularían ese territorio, los rasgos que podrían definir la explotación económica de dichas tierras o los posibles ejes viarios y de intercambio así como su relación con el emplazamiento de determinados núcleos indígenas.

Ahora bien, una vez valorado el interés de un enfoque de estudio como el propuesto, cabría atender a la segunda de las cuestiones anteriormente indicadas, y tratar de encuadrar brevemente dicho enfoque en el conjunto de aquellos trabajos que han abordado el análisis del mundo ibérico desde esa misma perspectiva, planteando, al mismo tiempo, la actual situación de los estudios ibéricos en el área regional.

\section{El estudio del mundo ibérico murciano: las comarcas de lorca y del noroeste}

Como hemos podido advertir, la amplia variedad de aspectos que entra en juego en un estudio como el que proponemos implica, necesariamente, el manejo de una gran variedad y cantidad de datos, junto a los que no podemos dejar de indicar aquellos aportados por la propia investigación del mundo ibérico y romano en este área del Sureste peninsular. Será en base a ellos en función de los que podamos llevar a cabo una primera aproximación a las áreas de estudio y al contexto histórico - cultural en el que nos movemos, siendo también estos los que nos permitirán advertir aquellos aspectos que pueden resultar de mayor interés a la hora de abordar un análisis del mundo ibérico en estos territorios del Sureste.

Tal y como apuntábamos anteriormente, los últimos trabajos llevados a cabo en las vecinas tierras alicantinas, valencianas y andaluzas, han puesto de manifiesto las posibilidades que ofrece el análisis del poblamiento ibérico para comprender no sólo la articulación del mismo y los modelos sociopolíticos y económicos que podrían caracterizar a cada una de dichas áreas, así como las similitudes y contrastes que se aprecian entre ellas, permitiendo advertir posibles ámbitos culturales diferenciados y territorios políticos distintos, que influirán de forma decisiva en el posterior proceso de integración de estas tierras en el mundo romano.

Así, por ejemplo, los trabajos desarrollados en el ámbito interior alicantino han puesto de manifiesto una clara jerarquización del poblamiento, en la que el núcleo instalado en La Serreta de Alcoy se constituirá, en el siglo III a.C., en el centro principal de todo este área, al que quedarán vinculados establecimientos de carácter secundario. Su patrón de asentamiento, caracterizado por ocupar un lugar clave en el territorio, será también uno de los elementos que favorecerán su desarrollo en época ibérica. Frente a él encontraríamos, además, toda una serie de centros de carácter secundario y de extensión menor. Por un lado, aquellos que, con una superficie que 
oscilaría entre 1,5 y 4 hectáreas, ofrecerían decisiones locacionales marcadas por su claro carácter estratégico; por otro, un conjunto de establecimientos cuyo patrón de asentamiento, ocupando zonas bajas, y próximas a los recursos agropecuarios, permite ver en ellos centros de clara vocación agrícola, destinados a la explotación de esos territorios y, probablemente, en función de ese patrón de asentamiento y de su menor entidad, vinculados también a ese oppidum principal $^{14}$.

El propio patrón de asentamiento que reflejan todos y cada uno de los centros de este área, parece reflejar, así, una organización del territorio definida por una clara estrategia defensiva de carácter conjunto, en el que todos y cada uno de esos núcleos secundarios, y siempre en relación con ese centro principal, controlarán los puntos clave de paso y los ejes de comunicación que permitirían el acceso a este territorio ${ }^{15}$.

En este ámbito alicantino, sin embargo, será precisamente la posición central, así como su papel de núcleo organizador de estas tierras aquellos factores que, probablemente, explicarían la desaparición del centro instalado en La Serreta, tras la llegada de Roma. Esta, intentará desarticular ese sistema organizativo indígena, acabar con aquellos yacimientos que, como el citado, podrían suponer un obstáculo a sus intereses, y transformando claramente el patrón de asentamiento y el modelo de poblamiento de época ibérica ${ }^{16}$.

El análisis de los patrones de asentamiento, ha llevado también a plantear, en el caso del mundo ibérico andaluz, la existencia de diversos modelos de organización sociopolítica del territorio. En este sentido, el estudio de aspectos tales como la localización de muchos de ellos, los rasgos que definen su emplazamiento, las posibles condiciones defensivas, su extensión, o su posible relación visual con otros centros, así como su posición con relación a los recursos agrícolas y a los ejes viarios, ha permitido diferenciar distintas tipologías y jerarquías de establecimientos.

En el valle y en la campiña del Guadalquivir, y partiendo de la dispersión que ofrece dicho poblamiento, así como del carácter de los distintos centros, especialmente de aquellos que parecen corresponder a núcleos de primer orden, se ha definido dos modelos de organización del poblamiento, que, además, han sido incluso puestos en conexión, en el área de Jaén, con posibles proyectos territoriales de tipo

14 GRAU, op. cit., 2003, pp. 55-59; GRAU, I. «El territorio septentrional de la Contestania», en Jornadas de Arqueología 'La Contestania Ibérica, treinta años después'. Alicante, 2005, pp. 77-82; GRAU y MORARALLA, op. cit., 2004, pp. 111-118.

15 GRAU, op. cit, 2004, pp. 68-72.

16 GRAU, op. cit., 2003, pp. 59-61; GRAU, op. cit., 2005, pp. 77-82; MORATALLA, op. cit., 2005, pp. 107; RUIZ, A. «Origen y desarrollo de la aristocracia en época ibérica, en el alto Valle del Guadalquivir», en Les Princes de la Protohistoire et l'émergence de l'état. Actes de la table ronde internationale organisée par le Centre Jean Bérard et l'École française de Rome, Naples, 27-29 octobre 1994. Nápoles-Roma, 1999, pp. 104-105. 
étnico, superiores a los meramente locales o comarcales que pudieron desarrollarse en otros ámbitos ibéricos, como en el propio área regional ${ }^{17}$.

Así, se ha planteado la existencia básica de dos modelos principales, el denominado polinuclear y el mononuclear. El primero de ellos, definido de forma más clara en el Alto Guadalquivir, se presentaría como el resultado de un proceso de creación y consolidación de territorios políticos por parte de los núcleos principales de dicho territorio. Varios son los elementos clave que definirían dicho modelo, destacando, especialmente dos. Por un lado, la presencia de un oppidum central, donde residiría la élite indígena. Su patrón de asentamiento vendría así definido por su emplazamiento en una posición destacada dentro el territorio y, sobre todo, con respecto al resto de asentamientos, frente a los que se mostraría, así, como un claro punto de referencia. Asimismo, presentaría, además, excelentes condiciones defensivas y ejercería un claro control visual de las tierras y ejes viarios naturales e, indirectamente, de las actividades productivas de explotación y de intercambio.

Por otra parte, cabría indicar la existencia de una serie de núcleos de carácter secundario, pero cuyo patrón de asentamiento y su propio carácter permitiría también definirlos como oppida, aunque de segundo rango, cuya finalidad sería colonizar y explotar todo el amplio territorio controlado desde ese centro principal ${ }^{18}$.

Por lo que respecta al modelo mononuclear, parece tener su más claro reflejo en el ámbito de Andalucía oriental, caracterizado por la presencia de un único centro principal, y por un amplio conjunto de núcleos de carácter secundario y de diversidad entidad, que, en base a los rasgos que definirían su patrón de asentamiento y su propio carácter, podrían encuadrarse a distintos niveles dentro de la jerarquía de poblamiento ${ }^{19}$. Entre ellos, un importante número correspondería a centros de reducida extensión, inferior, en muchos casos, a 0,25 hectáreas, y cuyo emplazamiento y proximidad denotaría, claramente, la vocación agropecuaria y el carácter secundario de los mismos frente a dicho oppidum principal.

17 RUIZ, op. cit., 1999, pp. 104-105; RUIZ, A. y MOLINOS, M. «El proceso histórico de los iberos en el valle alto del río Guadalquivir», en MOLINOS, M. y ZIFFERERO, A. (a cura di): Primi popoli d'Europa. Proponte e riflessioni sulle origini della civiltà nell'Europa mediterranea. Atti delle Riunioni di Palermo (14-16 ottobre 1994) e Baeza (Jaén) (18-20 dicembre 1995). Firenze, 2002, pp. 292; RUIZ, A. y SANMARTÍ, J. «Models comparats de poblament entre els ibers del nord i del sud», en Territoris Antics a la Mediterrània i a la Cossetània oriental. Actes del Simposi Internacional d'Arqueologia del Baix Penedès. El Vendrell, del 8 al 10 de novembre de 2001. Barcelona, 2003, pp. 42-43.

18 RUIZ y SANMARTÍ, op. cit., 2003, pp. 46-47; RUIZ, op. cit., 1999, pp. 99.

19 RUIZ y SANMARTÍ, op. cit., 2003, pp. 43-44; RUIZ, A. «Los príncipes iberos: procesos económicos y sociales», en ARANEGUI GASCÓ, C. (Ed.): Actas del Congreso Internacional. Los Iberos. Príncipes de occidente. Las estructuras de poder en la sociedad ibérica. Barcelona, 1998, pp. 294-295 y 298-299. 
Por último, y para el caso concreto del mundo ibérico valenciano, el análisis del poblamiento y de los patrones de asentamiento ha permitido diferenciar, en el área concreta del entorno de Edeta, entre varios niveles de asentamientos que reflejan la jerarquización que también debió definir este área peninsular durante este periodo, apuntando, además, a la posible organización territorial organizada desde dicho centro principal.

De este modo, $\mathrm{H}$. Bonet establece una clara diferenciación entre los diversos tipos de asentamientos documentados. Entre ellos, destaca, de forma especial, el núcleo que se hallaría a la cabeza de todo ese territorio, el Tossal de Sant Miquel, con aproximadamente 10 hectáreas de extensión y que debió ejercer un claro control político y económico de todo este área. Junto a él, se localizan, instalados en cerros de escasa altitud y en zonas bajas, y próximos a áreas de claro carácter y de amplias posibilidades agrícolas, toda una serie de establecimientos de tipo secundario, que define como aldeas o poblados, y de extensión menor, que puede oscilar entre las 2 y las 5 hectáreas, así como un cierto número de caseríos o granjas fortificadas, de tamaño aun menor pero que también tendrían un carácter esencialmente rural.

Finalmente, quedaría un importante número de establecimientos que reflejan un patrón de asentamiento definido, claramente, por criterios de tipo estratégico. Dicho patrón, estaría así caracterizado por emplazamientos en puntos de montaña claves para el control de determinados ejes viarios, con una amplia visibilidad del entorno, una clara intervisibilidad entre ellos y dominando a todos esos núcleos agrícolas y a las tierras explotadas por aquellos ${ }^{20}$. Todos estos establecimientos, definidos como fortines, así como esos distintos niveles de asentamientos indicados, han permitido, a su vez, una primera aproximación a las estrategias de organización, control y defensa territorial que, en época ibérica, pudieron caracterizar a este ámbito peninsular y, en general, al territorio de la ciudad de Edeta. Del mismo modo, también el análisis del patrón de asentamiento ha sido de gran interés para abordar el estudio de los espacios sacros, ya que, como señala H. Bonet, la organización de estos, es coherente con el esquema que refleja aquel ${ }^{21}$.

Los estudios sobre el poblamiento ibérico han ofrecido así, en estas áreas peninsulares, así como en otras muchas, interesantes datos sobre aspectos de tipo social, político, económico y cultural. A pesar de ello, desgraciadamente, no contamos con

20 BONET, H. «Los iberos en las comarcas centrales valencianas», en LORRIO, A. J. (Ed.): Los Iberos en la comarca de Utiel-Requena (Valencia). Valencia, 2001, pp. 69-70; MORET, P. «Fortifications ibériques tardives et défense du territoire en Hispaine Citérieure», en MORILLO, A., et al. (Coord.): Defensa y territorio en Hispania de los Escipiones a Augusto (Espacios urbanos y rurales, municipales y provinciales). Actas del coloquio celebrado en la Casa de Velázquez (19-20 marzo 2001). Universidad de León / Casa de Velázquez, 2003, pp. 175.

21 BONET, H. y MATA, C. «Lugares de culto Edetanos. Propuesta de definición», Quaderns de Prehistòria i Arqueologia de Castellò, 18, 1997, pp. 139-140. 
ningún enfoque que, partiendo de ese estudio del paisaje y centrándose en el análisis del poblamiento y de los patrones de asentamiento de época ibérica, haya abordado estos aspectos para el caso concreto del mundo regional.

$\mathrm{Si}$ bien es cierto que disponemos de diversos trabajos que abordan, de forma particular, múltiples aspectos del mundo ibérico murciano, especialmente aquellos relacionados con su cultura material, con la presencia de determinadas importaciones así como con el propio ámbito funerario, sólo el trabajo de P.A. Lillo, publicado en 1981, supone un primer intento de lograr una visión global de la cultura ibérica partiendo del estudio del poblamiento ${ }^{22}$, sin contar, desgraciadamente, esta misma línea de trabajo con una cierta continuidad a lo largo de las décadas siguientes. De este modo, los estudios sobre los paisajes ibéricos regionales no han experimentado el impulso que, como señalábamos, ha caracterizado los mismos en otras áreas peninsulares. En estas, el panorama cada vez más completo y complejo que parece definir, en base a los últimos trabajos, esos paisajes ibéricos, ha puesto aun más claramente de manifiesto el nulo conocimiento que tenemos de ellos en el área regional, y, muy especialmente, la necesidad de abordar un trabajo en esta línea que, siguiendo las nuevas perspectivas de trabajo y los enfoques planteados en los últimos años, tal y como veíamos, aborde ya no sólo el estudio del poblamiento desde el punto de vista de los núcleos principales, como hiciese P.A. Lillo, sino, de forma global, desde un punto de vista diacrónico y, partiendo del análisis de dicho poblamiento, atender a cuestiones de todo tipo, socio-políticas, económicas, simbólicas y culturales.

Del mismo modo, también en esta línea resultará interesante abordar la romanización de estas tierras, aspecto, asimismo, analizado siempre desde una óptica totalmente distinta y que debemos comprender, como un proceso lento y paulatino de intercambio recíproco y de transformación de esas comunidades y paisajes indígenas, cuyo mejor reflejo quedará además de manifiesto en la propia evolución del poblamiento y en los cambios que mostrará el nuevo patrón de asentamiento romano con respecto a los criterios que definían este en época ibérica.

A ello cabría añadir, asimismo, la ausencia de trabajos que aborden el estudio del mundo ibérico en las dos comarcas indicadas, como son el Campo de Lorca y el Noroeste murciano, y en las que, sin embargo, contamos con importantes yacimientos y hallazgos que reflejan el desarrollo del mismo ya desde el siglo $V$ a.C., que contrastaría, además, con los últimos estudios que han abordado los paisajes ibéricos en las vecinas tierras alicantinas y andaluzas, como en Los Vélez o la Puebla de Don Fabrique ${ }^{23}$.

22 LILLO, P.A. El poblamiento ibérico en Murcia, 1981.

23 GRAU, I. La organización del territorio en el área central de la Contestania Ibérica. Alicante, 2002; MARTÍNEZ y MUÑOZ, op. cit., 1999; ADROHER, A. y LÓPEZ, A. El territorio de las altiplanicies granadinas entre la Prehistoria y la Edad Media: arqueología en Puebla de Don Fadrique (19952002). Sevilla, 2004. 
Así, en función de todo lo indicado, tanto por sus objetivos y el marco espacial y cronológico en los que se centra, así como por la propia perspectiva planteada y el enfoque general, se trataría de un trabajo distinto a aquellos que, hasta el momento, han definido el estudio del mundo ibérico regional y de la integración de estas tierras en la órbita de Roma. De este modo, y si bien, como veremos, los propios datos de que disponemos no nos permiten sino plantear, únicamente, hipótesis de trabajo, que necesitarán ser contrastadas mediante nuevas investigaciones y, sobre todo, mediante nuevos trabajos de campo, consideramos también necesario y de gran interés llevar a cabo una primera aproximación al mundo ibérico regional desde este punto de vista.

\section{4. ¿Cómo llevar a cabo un estudio del mundo ibérico regional? Los sig como herramienta de trabajo y de análisis}

Una vez planteadas las bases teóricas de nuestra investigación y los objetivos de la misma, cabría plantearse cómo abordar el estudio de esos dos territorios murcianos indicados y, concretamente, del poblamiento y aquellos aspectos que determinarían el patrón de asentamiento ibérico en los mismos. En este sentido, debemos atender a tres cuestiones básicas: por un lado, el tipo de datos de que disponemos, por otro, sus límites y posibilidades, y, finalmente, la gestión y el análisis de los mismos.

\subsection{La recogida y valoración de los datos como punto de partida}

En general, entendemos esos datos, en sentido amplio, como toda aquella información, que nos aporte un mínimo y válido conocimiento sobre alguno de los múltiples aspectos que entran en juego en nuestro estudio y que nos ayuden a conocer y comprender mejor los criterios que definen el patrón de asentamiento ibérico de los distintos yacimientos documentados en estos territorios. Entre dichos datos, incluimos, sobre todo al referirnos a aquellos que formarán parte destacada en los diversos análisis propuestos, tanto aquella información primaria o básica, como la que derivaría del tratamiento y de la integración de la misma ${ }^{24}$.

La primera cuestión que se plantea es la que respondería a la recogida de esos datos, la cual se presenta, a su vez, ampliamente condicionada por el tipo de información de la que disponemos y que pretendemos integrar en nuestro trabajo. En este sentido, la variedad de aspectos que entra en juego en un estudio como el que proponemos implica, el manejo de una enorme cantidad y diversidad de información de todo tipo, en la que encontramos, así, datos de lo más variados y que deben tener un tratamiento particular en cada caso.

24 GRAU, op. cit., 2002, pp. 25; MACCHI, op. cit., 2001, pp. 9. 
Entre dicha información cabría distinguir, por un lado, aquella referida a las propias características físicas y geográficas que definen ambas áreas de estudio, y por otro, los datos derivados del propio registro arqueológico, que constituirán un elemento esencial en nuestro análisis de estos dos territorios murcianos, ayudándonos a comprender, además, el marco histórico - cultural en el que se mueve nuestra investigación. Finalmente, quedarían aquellos datos que nos puede ofrecer la propia documentación escrita, tanto aquella de época antigua, especialmente los textos de los autores clásicos, como la más reciente, tal como itinerarios de época moderna, información sobre el uso tradicional de los caminos, rutas ganaderas y vías de comunicación.

A grandes rasgos, consideramos que esos tres ámbitos de recogida de datos nos aportarán quizás una visión más completa que la que podría ofrecer cada uno de ellos por separado y, en especial, aquellos aportados por el registro arqueológico, en muchas ocasiones, escasos y fragmentarios. Recordemos, en todo caso,

Atendamos así, más brevemente, a los diversos datos que constituyen el punto de partida de nuestro trabajo, recordando, en todo caso, que serán fundamentalmente aquellos referidos a la propia documentación arqueológica, así como los relativos al medio físico y a los propios rasgos geográficos de estas tierras murcianas, los que tendrán un especial interés a la hora de llevar a cabo los diversos análisis que plantearemos más adelante.

\subsubsection{Datos sobre el medio físico}

Uno de los primeros aspectos a destacar en relación a este tipo de datos, es el referido a los problemas que plantea el conocimiento preciso de aquellos rasgos que pudieron definir, el medio físico en ambas comarcas de estudio a lo largo de los diversos periodos en los que se centra nuestro trabajo. En este sentido, somos conscientes de las transformaciones que han afectado al medio natural y, especialmente, de aquellas de carácter ambiental que se han puesto de manifiesto a través de los estudios realizados en otros ámbitos territoriales del Sureste, como en las vecinas tierras almerienses.

En el caso de las dos comarcas murcianas indicadas, no contamos, desgraciadamente, con datos relativos a cuestiones de vegetación, clima, hidrología, etc., que condicionarían ampliamente la ocupación del espacio en estas tierras y que, sin embargo, sólo podemos conocer, muy parcialmente, a través de la escasa información que nos ofrecen las fuentes literarias y de los datos aportados por esos trabajos llevados a cabo en otros sectores peninsulares próximos a aquellas. Es por ello que debemos utilizar estos datos con mucha cautela en nuestra investigación, siempre a la espera de que futuros trabajos nos aporten un mejor conocimiento del medio que, en 
general, caracterizaría estas comarcas en época ibérica y romana.

A pesar de ello, sí que debemos utilizar en nuestro estudio los datos referidos a la propia orografía del terreno, elemento fundamental en dos comarcas caracterizadas por un relieve especialmente accidentado, así como también aquellos relativos a la red hidrográfica y los recursos de carácter hídrico, y, finalmente, los que afectarían al carácter de los suelos que encontraríamos en los diversos sectores comarcales. Estas tres cuestiones han condicionado ampliamente, a lo largo de toda su historia, la ocupación, la explotación y el propio carácter de estos territorios peninsulares.

Para todo ello no sólo disponemos de cartografías ya elaboradas y fotografía aérea, sino que también contamos con las curvas de nivel del terreno que nos permitirán la creación de un modelo digital del terreno y de diversos mapas de pendientes a partir de los cuales llevar a cabo, también, muchos de los análisis que veremos a continuación.

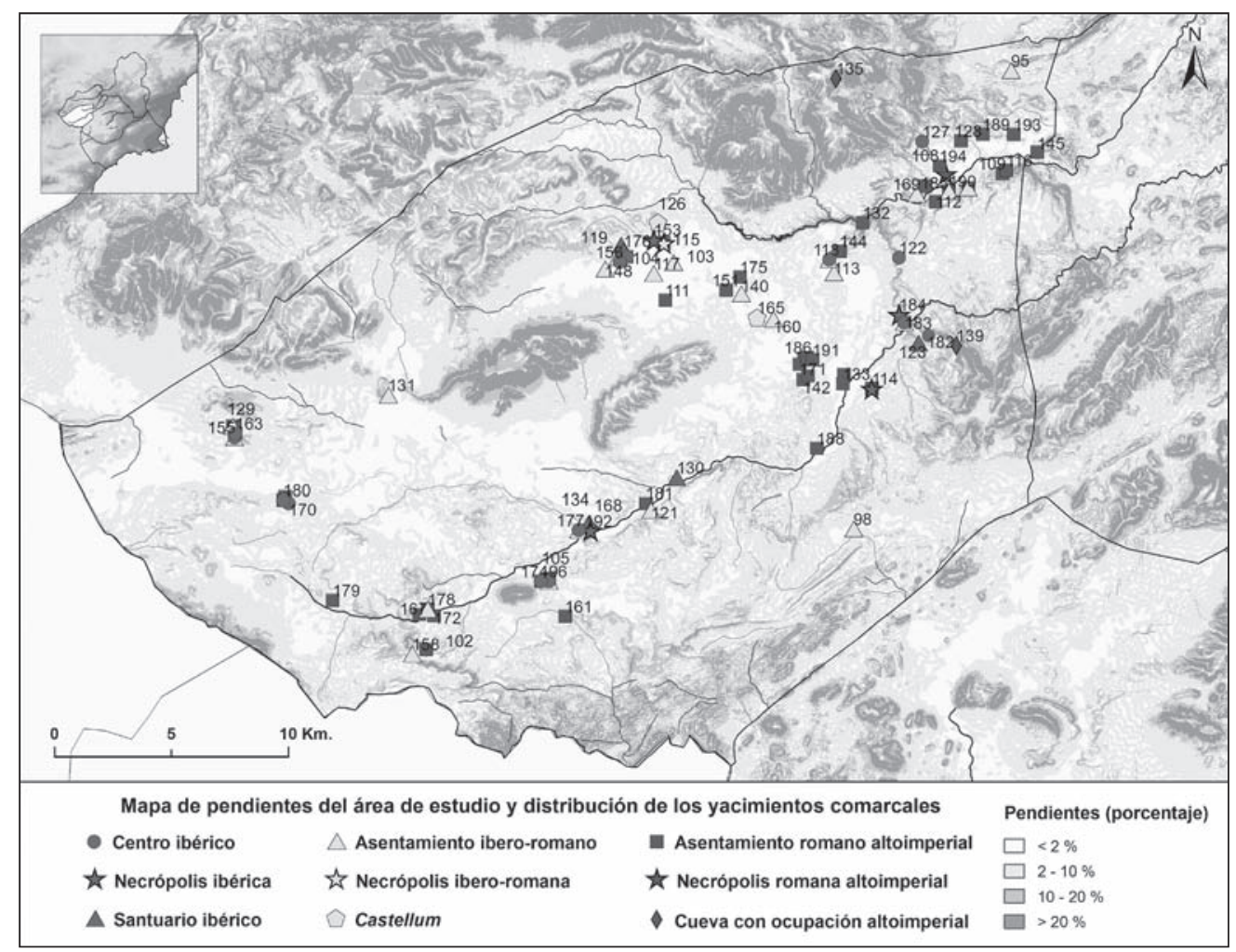

Figura 1. Mapa de pendientes en la comarca del Noroeste murciano y localización de los principales yacimientos ibéricos y romanos. 
Aun así, y al margen de los datos que todas esas cartografías, documentación y estudios puedan ofrecer sobre el medio físico en ambas comarcas, consideramos fundamental la necesidad de acudir a estos territorios y conocerlos de primera mano a la hora de llevar a cabo un estudio del paisaje y del desarrollo histórico de los mismos. Sólo así es posible comprender, de forma clara, el modelo de ocupación y explotación que, tradicionalmente, ha caracterizado y define aun, en determinados sectores más aislados de los principales núcleos de población, estas tierras regionales, así como los rasgos que jugarían un papel fundamental en la configuración de los paisajes comarcales a lo largo de la historia.

\subsubsection{Datos de tipo documental}

Un segundo tipo de datos que hemos integrado en nuestro trabajo son aquellos que podríamos denominar, a grandes rasgos, y en un sentido amplio, de tipo documental, entre los que quedaría englobada una amplia variedad, tanto en base a su origen como a la información que ofrecen. Aun así, todos ellos tendrían, en general, un carácter complementario que ayudará a completar y valorar el resto de los datos indicados.

Dentro de este segundo conjunto se encuadrarían todos aquellos procedentes de textos escritos, aunque, claro está, correspondientes a diversos momentos históricos $\mathrm{y}$, por tanto, con unas características y condicionamientos muy diversos en cada caso de los que debemos ser muy conscientes.

Entre todos ellos podríamos destacar, sobre todo, la información que nos ofrecen las fuentes grecolatinas sobre el Sureste peninsular, y que, a pesar de la problemática que encierra, diversa además en cada caso, constituye un punto de partida de especial interés para conocer estos territorios durante los periodos de estudio.

Asimismo, no podemos tampoco dejar de indicar aquellos textos de épocas más recientes que nos informan sobre el mundo regional y sobre las comarcas de estudio, tales como aquellas fuentes del periodo medieval, que en otros ámbitos del Mediterráneo, como en el mundo itálico, han ofrecido importantes datos para el conocimiento de época protohistórica ${ }^{25}$, y que resultan de gran interés para aproximarnos a la ocupación del territorio y el patrón de asentamiento en el área lorquina.

También otros documentos y obras de época moderna y contemporánea aportan interesantes datos sobre las comarcas analizadas, así como sobre el propio medio físico y el poblamiento en las mismas, entre los que no podemos olvidar los reperto-

25 LEONARDI, G. «Assunzione e analisi dei dati territoriali in funzione della valutazione della diacronia e delle modalità del popolamento», en BERNARDI, M. (a cura di): Archeologia del Paesaggio. IV ciclo di lezioni sulla ricerca applicata in Archeologia. Certosa di Pontignano (Siena), 14 - 26 gennaio 1991. Quaderni del Dipartimento di Archeologia e Storia delle Arti, sezione archeologica - Università di Siena 1. Firenze, 1992, pp. 25-66. 
rios de caminos y relatos de viajeros de los siglos XVI - XVIII, la información que sobre la explotación de estas tierras y sus recursos ofrecen el Catastro de Ensenada o el Diccionario geográfico-estadístico-histórico de P. Madoz, y los datos que recogen obras como las de D. Jiménez de Cisneros, M. González Simancas y J. M. Munuera y Abadía, ya de inicios del siglo XX.

\subsubsection{Datos de tipo arqueológico}

Finalmente, y junto a los dos conjuntos de datos indicados, quedaría por señalar aquellos referidos a la documentación de tipo arqueológico de la que disponemos. El distinto origen de esta, procedente tanto de excavaciones de urgencia, como de trabajos sistemáticos de campo y de simples hallazgos aislados, como el conocido centauro de Los Royos, condiciona también, en gran medida, la información aportada por estos datos.

En cualquier caso, un importante conjunto de los materiales recuperados proceden de trabajos de prospección realizados en ambas comarcas con el objetivo de la realización de la Carta Arqueológica de la Región, que será básica a la hora de afrontar nuestro trabajo, teniendo presentes, además, los últimos cambios que, en los últimos años, se están incluyendo en la revisión de la misma llevada a cabo por el Servicio de Patrimonio Histórico de la Región de Murcia.

El principal rasgo que define a la mayor parte de estos datos, y que, en gran medida, condiciona su análisis, es su amplia variedad, especialmente si atendemos al contexto en el que pueden encuadrarse, sectores de hábitat, espacios de culto, áreas funerarias, puntos de control y vigilancia militar, o espacios de carácter muy concreto, como sería el caso de la denominada casa - fuerte de Los Paradores, en Caravaca. Asimismo, suponen también un amplio conocimiento ya no sólo de la propia cultura material recuperada sino, además, de otras muchas cuestiones que giran en torno a elementos como los restos funerarios monumentales hallados en Coy, el carro ibérico localizado en el Cerro del Castillo de Lorca, los restos constructivos, arquitectónicos y decorativos localizados en algunos de los yacimientos comarcales, así como los miliarios e inscripciones hallados en el ámbito lorquino o en las proximidades del área de La Encarnación.

Para la recogida minuciosa de todos estos datos, y especialmente de aquellos relativos a la cultura material documentada en dichos centros, hemos recurrido a los diversos museos municipales en los que se halla depositada la mayor parte de ellos, centrándonos, especialmente, en aquellos relativos a los periodos ibérico y romano en cada una de las comarcas de estudio, pero también tomando en consideración los de otros momentos históricos, teniendo siempre presentes las posibilidades que puede ofrecer el planteamiento de analogías a la hora de definir, de forma más precisa, 
determinados criterios caracterizadores, por ejemplo, de la decisión locacional de determinados núcleos ${ }^{26}$.

En todo caso, no siempre estos datos nos permiten obtener un conocimiento preciso de todos y cada uno de dichos yacimientos, por lo que será necesario, en determinados casos, atender a otras cuestiones tales como su patrón de asentamiento o su dominio visual del entorno, para aproximarnos, quizás, al carácter de algunos de ellos.

El objetivo principal es, por tanto, recopilar y conocer todos estos datos, así como los rasgos que definen su contexto arqueológico y cultural, y su posible carácter, con el objetivo de poder integrarlos en el estudio que planteamos, para lo cual, los Sistemas de Información Geográfica, supondrán una herramienta fundamental. Estos, nos permitirán no sólo poner en conexión todos y cada uno de ellos, sino también, integrar esa información arqueológica junto con aquella que ofrece el propio medio físico y la documentación escrita, permitiéndonos así abordar múltiples aspectos, tanto sociales, como económicos, políticos, culturales, etc. En este sentido, por ejemplo, la presencia destacada de cerámicas de almacenamiento entre los materiales recuperados, y la propia localización de un yacimiento en un emplazamiento con suelos y recursos aptos para el desarrollo de las actividades agrícolas, podría ofrecer datos indirectos relativos aspectos como la propia economía o la explotación del territorio desarrollada por dicho centro, criterios fundamentales a la hora de comprender el patrón de asentamiento de dichos núcleos. Asimismo, el propio volumen y la diversidad de todos ellos, ponen de manifiesto la complejidad y amplitud que requiere un análisis en esta línea, así como los propios límites que este impone, de los que debemos ser especialmente conscientes.

\subsection{La problemática que encierran los datos de partida}

Tras la recogida de todos y cada uno de los datos indicados, y teniendo presentes las propias dificultades y condicionamientos que caracterizan el uso de los mismos en nuestra investigación, ha sido necesario llevar a cabo, también, una valoración crítica de dichos datos. Ante todo, debemos conocer cuales son aquellas informaciones más problemáticas o con las que debemos ser especialmente cautelosos, ya que plantearemos nuestro análisis de los mismos y su posible interpretación dentro del marco general de nuestro estudio en función de todo ello ${ }^{27}$.

26 HODDER, I. Interpretación en arqueología. Corrientes actuales. Barcelona, 1994, pp. 111; CRIADO, F. Del Terreno al Espacio: Planteamientos y perspectivas para la Arqueología del Paisaje, CAPA (Criterios y Convenciones en Arqueología del Paisaje) 6. Santiago: Grupo de Investigación en Arqueoloxía da Paisaxe, 1999, pp. 12-13; MACCHI, op. cit., 2001, pp. 13; COLECCHIA, A. «Metodi di approccio al territorio per lo studio del paesaggio antico. L'esperienza nelle giudicarie esteriori (TN) dall'aerofotointerpretazione all'indagine sul terreno», Archeologia Medievale XVIII, 2001, pp. 7-14.

27 CRIADO, op. cit., 1999: pag. 5, nota 5; FÁBREGA, op. cit., 2004, pp. 15-16. 
En general, varios han sido los datos que han ofrecido más problemas a la hora ya no sólo de su recogida, sino, también de su integración en nuestro estudio. En primer lugar, debemos señalar los propios datos relacionados con el conocimiento del medio físico y ambiental que pudo caracterizar estas tierras regionales durante los periodos de estudio, especialmente, por la escasez de trabajos que hayan abordado el análisis paleoambiental de estas dos comarcas, así como por la ausencia de cartografías concretas referidas a la potencialidad de sus suelos, que quizás habrían resultado especialmente indicativas a la hora de abordar determinadas cuestiones de nuestro trabajo.

A pesar de ello, creemos que es posible, al menos a grandes rasgos, advertir aquellos sectores que pudieron resultar, quizás, más aptos para la explotación agrícola durante los periodos de estudio, así como aquellas áreas que tendrían un carácter forestal, hoy muy degradadas y, en muchos casos, repobladas, pero que, probablemente, y tal y como indican los propios datos de siglos pasados, como el propio Diccionario geográfico-estadístico-histórico de España y sus posesiones de ultramar de $\mathrm{P}$. Madoz o el Catastro de Ensenada, debieron alcanzar, en ambas comarcas, y muy especialmente en el Noroeste, una amplia extensión, constituyendo parte fundamental de la vida de los habitantes de estas tierras.

Del mismo modo, hemos recurrido a cartografías referidas a cuestiones de tipo edafológico, a las propias pendientes de cada área de estudio, a los usos tradicionales del suelo y a los posibles cambios que se advierten en muchos de esos aspectos con respecto a los datos que, sobre ellos, nos ofrece también esa documentación escrita indicada y algunos de los escasos estudios paleoambientales de los que disponemos para determinados yacimientos de estas áreas.

Asimismo, también los datos arqueológicos recogidos en ambas comarcas han presentado sus propias dificultades a la hora de integrarlos en nuestro estudio. $\mathrm{Su}$ limitado número, la escasa información que muchos de ellos ofrecen, los errores de localización de determinados yacimientos, así como la ausencia de trabajos de campo sistemáticos en la mayor parte de ellos, nos impiden un conocimiento más preciso sobre muchos de esos yacimientos y sobre cuestiones tan importantes como su extensión y su cronología.

A todo ello cabría sumar, además, la heterogeneidad de todos ellos, tanto en relación a las condiciones en las que debemos encuadrar su hallazgo, como por las amplias diferencias que se advierten entre ambos territorios de estudio, en cuanto a cantidad y fiabilidad de los datos documentados. A pesar de ello, también este aspecto puede, sin embargo, resultar de interés a la hora de comprender la evolución de dichas áreas murcianas y las posibles diferencias que marcan la dinámica poblacional y económica en estas comarcas a lo largo de los periodos de estudio.

Por último, cabría señalar, en conexión con esos datos arqueológicos, que también la toponimia de muchos de los núcleos documentados ha ofrecido problemas, 
haciendo necesaria una amplia revisión de todos ellos en este sentido, a lo que cabría añadir la propia localización de determinados yacimientos, hoy desconocida o, en ocasiones, tan próxima, que podrían pertenecer, más que a dos núcleos distintos, a dos ocupaciones de un mismo centro en dos periodos diversos.

En cualquier caso, todos estos problemas y limitaciones que ofrecen los datos no deben llevarnos a dejar muchos de ellos al margen de nuestro análisis. Así, si bien no todos podrán valorarse de igual modo y ser tratados de forma homogénea, lo cierto es que no conocemos, hasta qué punto, su análisis puede revelar el valor intrínseco de cada uno de ellos y si al abordar todos ellos en conjunto, podrían ofrecer interesante información sobre múltiples aspectos relativos al patrón de asentamiento de esos centros a los que, quizás, resultaría complicado aproximarse desde un mero análisis particular de cada uno de aquellos ${ }^{28}$.

Del mismo modo, dicha problemática, nos obliga, por así decirlo, a partir, ya desde el inicio de nuestro trabajo, de la necesidad de abordar el análisis de estas tierras regionales, siempre, desde una perspectiva comparativa, que permita, tal vez así, completar los posibles vacíos encontrados en la documentación de cada una de dichas áreas de estudio, y comprender algunos de los aspectos que, quizás, sólo muy superficialmente, quedarían de manifiesto en el modelo de ocupación del territorio que se observa en cada una de ellas.

Ahora bien, una vez conocidos los datos y su problemática, cabría preguntarse cómo podríamos organizarlos e integrar todos ellos para su análisis. Es precisamente aquí donde entran en juego los Sistemas de Información Geográfica, que no sólo ofrecerán amplias ventajas para integrar información totalmente heterogénea, sino que, también, facilitarán su posterior manejo, tratamiento y análisis.

\subsection{Los sig como herramienta de trabajo: la organización, integración y análisis de los datos}

Uno de los primeros aspectos que se plantean, una vez que tenemos claros los datos de los que disponemos, es cómo integrar todos ellos en un SIG. El principal problema viene de la mano, especialmente, de aquellos datos de tipo arqueológico, siendo fundamentalmente estos los que debemos recopilar y elaborar para su posterior tratamiento a través de un Sistema de Información Geográfica. En este sentido, es fundamental partir de una visión diacrónica de los mismos que encaje con los objetivos de nuestro trabajo y que nos permita, además, establecer una visión compara-

28 MACCHI, op. cit., 2001, pp. 7-21; BOSCHETTI, M. et al. «Applicazioni GIS per l'archeologia: lo studio della distribuzione dei siti archeologici nel Garda meridionale», Archeologia Medievale XVIII, 2001, pp. 595-606. 
tiva entre los diversos periodos de estudio en los que se centrará nuestro análisis y, en cierta medida, encuadrar también ambos territorios en la dinámica que caracterizaría al resto de las tierras del Sureste peninsular en estas centurias.

Las dificultades parten de dos cuestiones esenciales: por un lado, la ausencia de trabajos previos que puedan suponer un punto de partida, en este sentido, para nuestro estudio y, por otro, la amplitud cronológica del periodo a analizar, que, desde el siglo V a.C., abarcaría hasta los momentos finales del II d.C. No podemos olvidar, ante todo, que sería un error tratar de aplicar, a priori, las periodizaciones establecidas para otros ámbitos peninsulares, ya que, en cada caso, es necesario atender a los rasgos propios que definen la evolución concreta y particular del territorio analizado, así como a su problemática específica.

Así, el planteamiento de un esquema cronológico general, que sirva de base a la integración y al posterior tratamiento y análisis de esos datos, es una de las primeras cuestiones a tener en cuenta, que partirá, además, de los propios datos ya recogidos y los rasgos que estos permiten ya observar en relación a la propia dinámica interna y a la evolución del poblamiento en cada una de las dos comarcas de estudio. Como se ha planteado también en otros ámbitos peninsulares y del Mediterráneo, los asentamientos, en tanto que lugares de encuentro de formas sociales, económicas y espirituales de una determinada comunidad, constituyen un elemento fundamental a la hora de comprender aquellos rasgos que definirían los modelos de ocupación y organización territorial, así como, en última instancia, la propia evolución del mismo y la configuración de los diversos paisajes históricos, por lo que, ha sido precisamente el poblamiento, y siempre sin olvidar otros muchos aspectos, el elemento principal a tener en cuenta a la hora de abordar un estudio como el que proponemos ${ }^{29}$.

Será así, en función del mismo, que también nosotros intentaremos establecer un esquema diacrónico de trabajo para abordar el análisis y la interpretación de todos esos datos ${ }^{30}$. Para ello, aspectos como la evolución de los distintos yacimientos documentados, su aparición o abandono, los rasgos que definen su patrón de asentamiento y las posibles transformaciones que se advierten en el mismo, o los cambios que ofrece el propio registro material de muchos de esos centros, han sido aspectos fundamentales a tener en cuenta a la hora de organizar, desde el punto de vista cronológico, los numerosos datos de que disponemos, antes de pasar a su análisis definitivo ${ }^{31}$.

De este modo, una vez recopilados y organizados dichos datos, en nuestro caso, desde una perspectiva diacrónica, en base a cuatro grandes periodos de análisis, cabría atender a una última cuestión. Nos estamos refiriendo a la integración de todos

29 MACCHI, op. cit., 2001, pp. 21.

30 SANTOS VELASCO, op. cit., 1994, pp. 13-15.

31 MACCHI, op. cit., 2001, pp. 13-14. 
esos datos en un Sistema de Información Geográfica que servirá de herramienta, ya no sólo para el propio tratamiento y trabajo con esa amplia variedad y cantidad de datos, sino, también, para abordar muchos de los aspectos que se nos plantean a la hora de analizar el poblamiento ibérico y romano en estos territorios y las transformaciones que se advierten en los patrones de asentamiento y la ocupación del territorio a lo largo de las diversas centurias en las que se centra nuestra investigación.

Los últimos trabajos que se están desarrollando no hacen sino poner de manifiesto, la utilidad de los Sistemas de Información Geográfica como herramientas fundamentales para el tratamiento, la integración y la organización de datos muy heterogéneos, así como también, para el análisis combinado de muchos de ellos. A ello cabe añadir, además, las posibilidades de aquellos para lograr generar nueva información a partir de la ya existente ${ }^{32}$, es decir, partiendo de los datos a los que nos referíamos con anterioridad. Estos representarían, siguiendo los tres niveles que establece G. Macchi en el proceso de análisis propuesto, el primero de ellos. El segundo, constituido por lo que denomina 'información', correspondería a aquellos datos derivados de los anteriores y generados partiendo de la combinación y el análisis de aquellos, siendo el último nivel el 'modelo' planteado en base a todo lo anterior ${ }^{33}$.

Es así, aquí, donde entran en juego los SIG y donde estos facilitarán la gestión, el manejo, la visualización y el análisis de todos esos datos, así como la obtención de nueva información a partir de aquellos. El uso de los Sistemas de Información Geográfica, nos permitirá, además, abordar todos ellos de forma sincrónica y diacrónica, facilitando de este modo un análisis comparativo y, en definitiva, una visión de los mismos 'en el tiempo y en el espacio'. El objetivo es, por tanto, enfocar su uso a la comprensión de aquellos criterios que definirían la dinámica del poblamiento ibérico y romano en los territorios señalados, atendiendo asimismo a la relación que podría establecerse entre este y esos otros elementos que formarían parte del paisaje comarcal en cada periodo concreto, básica para aproximarnos, de forma más completa, a la ocupación de estas tierras y a la evolución del patrón de asentamiento en cada momento de estudio ${ }^{34}$.

Así, será precisamente desde esta perspectiva, desde la que pretendemos orientar el uso de los Sistemas de Información Geográfica en nuestro trabajo, intentando plantear, en función de los datos de que disponemos, de sus limitaciones, y de los propios objetivos de estudio, cuales serían aquellos análisis y aspectos que nos interesaría abordar partiendo de los SIG como herramientas de trabajo.

32 GRAU, op. cit., 2002, pp. 25; MACCHI, op. cit., 2001, pp. 9.

33 MACCHI, op. cit., 2001, pp. 9.

34 GRAU, op. cit., 2006, pp. 211-221; MAYORAL, op. cit., 2004, pp. 250-269. 
Estos, sin embargo, presentan también importantes límites que, quizás, al menos brevemente, cabría señalar, ya que también debemos tenerlos muy presentes en nuestro estudio. Así, por ejemplo, es fundamental valorar, en cada caso, en cada periodo, y en cada territorio, el interés de los diversos análisis que nos permiten llevar a cabo esos Sistemas de Información Geográfica, ya que resultaría un error tratar de analizar de forma idéntica todos los periodos de estudio y las distintas áreas indicadas.

Asimismo, no debemos atender tanto a los datos concretos que nos ofrecen dichos análisis, sino, más bien, a las tendencias generales que estos parecen marcar en cada periodo, aspecto este que nos ofrecerá una visión diacrónica de la evolución del poblamiento y la ocupación del territorio a lo largo de las diversas centurias analizadas. Sólo así será además posible trabajar con datos muy heterogéneos, también en cuanto a su cantidad se refiere, tal y como indicábamos anteriormente.

De este modo, y si bien somos conscientes, asimismo, de los diversos problemas que la utilización de esos SIG implica, así como de sus limitaciones, consideramos, sin embargo, que constituyen una eficaz herramienta para abordar un estudio como el que nos proponemos.

\subsection{Los sig y el análisis del poblamiento en las comarcas de estudio}

Si nos centramos ahora, ya de forma más particular, en la utilización concreta de los SIG en nuestro trabajo, cabría señalar tres aspectos fundamentales.

En primer lugar, debemos atender a los diversos niveles de análisis planteados y que abarcarían desde un análisis particular de cada yacimiento, en el que no sólo nos interesan sus propios rasgos internos, sino su papel en el contexto espacial y territorial en el que se integra ${ }^{35}$, hasta un análisis global y comparativo de ambos territorios y de los mismos con respecto a otros ámbitos del Sureste y del Levante peninsular.

Una segunda cuestión importante sería la referida al tratamiento que debemos hacer de todos y cada uno de esos datos, ya que, como indicábamos, resulta básico tener presente su diversidad a la hora de analizarlos. Así, por ejemplo, aspectos como la propia cronología de los mismos, su funcionalidad y carácter, diferenciando entre oppida, granjas, caseríos, castella o villae, así como su mayor o menor fiabilidad, deben ser tenidos en cuenta a la hora de integrar todos ellos en un Sistema de Información Geográfica. En este sentido, y si bien determinados datos pueden resultar especialmente problemáticos para determinados análisis, para otros, al margen de su fiabilidad, pueden ser de gran interés y ofrecer, en conjunto con el resto de los datos recopilados, interesante información.

35 MACCHI, op. cit., 2001, pp. 8; VICENT, op. cit., 1991, pp. 44-47. 
Por último, cabría atender a la aplicación concreta de los SIG en nuestro trabajo y en el análisis del poblamiento y, de forma especial, del patrón de asentamiento, en ambas comarcas de estudio.

En general, podríamos establecer una serie de análisis básicos que nos permitirían comprender, de forma más detenida que la mera observación, los distintos aspectos que estarían en clara relación con el emplazamiento de muchos de los asentamientos comarcales, y que, en definitiva, ofrecerían una imagen clara de aquellos criterios que definirían su patrón de asentamiento y las transformaciones que se advierten en él a lo largo de época ibérica y hasta el periodo altoimperial.

Desde este punto de vista, cabría atender a tres amplios aspectos de análisis que permitirán llevar a cabo esa primera aproximación a la evolución de dichos patrones de asentamiento a lo largo de los periodos de estudio. En primer lugar, aquellos referidos a la propia ocupación del espacio y a los rasgos que, de forma concreta, definen el emplazamiento de dichos núcleos, tales como altitudes, topografía, proximidad a determinados cursos de agua, etc. En segundo lugar, aspectos relativos, ya no sólo al emplazamiento en sí de esos núcleos, sino aquellos que estarían en conexión con el entorno de los mismos, y que caracterizarían la explotación y el aprovechamiento de las tierras que los rodean. Finalmente, cabría abordar aquellas cuestiones referidas a la apropiación y al modelo de organización del espacio reflejadas, a lo largo del periodo ibérico, en ese patrón de asentamiento, tal y como indicábamos al señalar esos otros ámbitos ibéricos levantinos y andaluces. Asimismo, no podemos olvidar tampoco las transformaciones que la llegada de Roma supondrá en ese modelo de ocupación y explotación del territorio, cuyo mejor reflejo quedará de manifiesto en los nuevos criterios que definirán el patrón de asentamiento en estas tierras del Sureste peninsular a partir del siglo I d.C.

4.4.1. Analizando la ocupación del espacio y los criterios básicos de la decisión locacional de los distintos yacimientos comarcales

Dentro de este conjunto de análisis se encuadrarían todos aquellos destinados a aproximarnos a los criterios que definieron la ocupación del territorio a lo largo de los diversos periodos de estudio. En este sentido, el objetivo de todos ellos no es sólo abordar el patrón de asentamiento de los núcleos de hábitat de ambas comarcas, sino también, intentar comprender la decisión locacional y los criterios que definen el patrón de emplazamiento de otro tipo de establecimientos, tales como los castella tardorrepublicanos que se localizan en la comarca del Noroeste murciano.

Para llevar a cabo todos ellos, será fundamental tener en cuenta aquellos aspectos relacionados con los propios rasgos físicos y ambientales del medio en el que se encuadran los diversos núcleos comarcales, ya que, como se ha señalado, su estudio 
puede aportar interesante información sobre las estructuras económicas y productivas, y sobre la propia mentalidad de sus habitantes y la percepción del paisaje por parte de $\operatorname{estos}^{36}$. Asimismo, también debemos tener presentes los datos arqueológicos antes indicados y aquellos de tipo documental.

No podemos olvidar, ante todo, y en conexión con todos esos datos, la importancia que determinados factores, como la proximidad a los recursos hídricos, a fértiles tierras de cultivo o el propio control de un sector de paso natural, pudieron tener en el emplazamiento de muchos de esos yacimientos, siendo quizás, un claro ejemplo, la localización de los santuarios ibéricos y la presencia de manantiales en sus inmediaciones.

Se aprecia claramente, si observamos la distribución de los distintos yacimientos comarcales, que, ya desde época prehistórica, la decisión de muchos de ellos pudo estar condicionada no sólo por las vías naturales de comunicación sino también por los propios recursos que han caracterizado esta zona del Sureste a lo largo de su historia. En este sentido, no podemos olvidar que ya en época argárica se han descrito como elementos determinantes en la localización de muchos asentamientos no sólo el control de una determinada ruta natural, sino también el de aquellas zonas aptas para el desarrollo de actividades agrícolas y ganaderas ${ }^{37}$. De este modo, una simple observación de la ocupación diacrónica del territorio en cada momento puede aportar ya destacada información sobre los criterios que constituyen la base fundamental para comprender el patrón de asentamiento de muchos de esos centros, así como sobre las transformaciones que definen cada uno de los periodos abordados y los intereses que caracterizarían a esos distintos yacimientos en cada momento.

Hemos generado así, partiendo de las curvas de nivel, un modelo digital del terreno, así como toda otra serie de capas secundarias, tomando también las cartografías a las que nos referíamos anteriormente, que, combinadas con los propios datos arqueológicos, nos ofrecen importantes datos relativos no sólo al patrón de asentamiento de muchos de los núcleos documentados en ambas comarcas, sino también sobre los posibles criterios que definirían su emplazamiento, incluidos aquellos de tipo estratégico, y que, de algún modo, condicionarían también, en determinados casos, su desarrollo a lo largo de las centurias estudiadas ${ }^{38}$.

36 CAMBI, F. y TERRENATO, N. Introduzione all'archeologia dei paesaggi. Roma, 2004, pp. 233.

37 AYALA, M. M. El poblamiento argárico en Lorca. Estado de la cuestión. Murcia, 1991, pp. 297.

38 VICENT, op. cit., 1991, pp. 82-83; HAGGET, op. cit., 1976, pp. 51-53, 83-89, 120-130 у 185; HODDER, op. cit., 1994, pp. 170-171; HODDER, I. y ORTON, C. Análisis espacial en arqueología. Barcelona, 1999, pp. 99-101 y 253-256; HIGGS, E.S. y VITA-FINZI, C. «Prehistoric economies: a territorial approach», en HIGGS, E. S. (Ed.): Papers in Economic Prehistory. Cambridge, 1972, pp. 33; CHISHOLM, M. Rural settlement and land use. Chicago/Londres, 1970, pp. 102-103 y 124-126; GAR- 
Varios son los aspectos que podemos analizar, así, partiendo de esas cartografías y capas secundarias generadas, tales como aquellos referidos a la ocupación del espacio, a la distribución del poblamiento ${ }^{39}$, la propia viabilidad, que pudo condicionar también dicha ocupación, la proximidad a determinados recursos, hídricos, agrícolas y forestales, el carácter de los suelos del entorno más inmediato a dichos centros y, en definitiva, los rasgos que definen el patrón de asentamiento de los principales núcleos de cada área de estudio ${ }^{40}$. Todas estas cuestiones nos permitirán, además, llevar a cabo una primera aproximación diacrónica a ambas comarcas y advertir los posibles cambios que supondrían la llegada de los primeros influjos itálicos y la posterior instalación romana en ellas.

El objetivo final de esos diversos análisis es, por tanto, el observar posibles transformaciones internas y las continuidades que caracterizarían el patrón de asentamiento y la ocupación del espacio en cada comarca a lo largo de los distintos periodos de estudio, informándonos además, indirectamente, de los intereses que pudieron definir la posterior ocupación romana de estas tierras y de los contrastes que, el nuevo paisaje romano, ofrecería con respecto al de época ibérica.

4.4.2. Analizando la explotación del medio y los rasgos económicos del poblamiento en ambos territorios de estudio.

Un segundo conjunto de análisis sería aquel relativo a los aspectos de tipo económico y relacionados con la explotación del territorio, claramente en conexión con esa ocupación del territorio abordada anteriormente y que, en gran medida, constituirán otra de las cuestiones básicas para comprender el patrón de asentamiento de esos centros y su evolución.

Es aquí donde cabría encuadrar, ya de forma más detenida, el análisis concreto de los posibles recursos que definen el entorno de esos centros ibéricos y romanos,

NER 1971: pag. 216-217; BOSCHETTI et al., op. cit., 2001, pp. 7-8; PARMEGGIANI y POSCOLERI 2001: pag. 196-220; MAYORAL FRANCO 1984: pag. 73-75; FÁBREGA, op. cit., 2004, pp. 16-18; GRAU, op. cit., 2005, pp. 328-330; GRAU, op. cit., 2006, pp. 213-221; BASILDO, R. M., GUTIÉRREZ PUEBLA, J. y RUIZ-GÁLVEZ, M. «Generación de un sistema de información geográfica», en RUIZ-GÁLVEZ PRIEGO, M. (Ed.): Territorio nurágico y paisaje antiguo. La meseta de Pranemuru (Cerdeña) en la Edad del Bronce Anejos de Complutum, vol. 10. Madrid, 2005, pp. 133 y 137; MARTIN, J.C., BERMUDEZ, J. y PERLINES, M.R. «Los Sistemas de Información Geográfica Aplicados a la Campiña de Córdoba: sincronías y diacronías poblacionales», en MARTíN DE LA CRUZ, J. C. y LUCENA MARTÍN, A. M. (Coord.): Actas del I Encuentro Internacional. Informática aplicada a la investigación y la gestión arqueológicas (Córdoba, 5-7 de mayo, 2003) I. Córdoba, 2004, pp. 211-235.

39 MACCHI, op. cit., 2001, pp. 7-21; BOSCHETTI et al., op. cit., 2001, pp. 595-606; ALLEN, M.J. «Analysing the landscape: A geographical approach to archaeological problems», en SCHOFIELD, A. J. (Ed.): Interpreting artefact scatters: Contributions to ploughzone archaeology. Oxford, 1991, pp. 54.

40 BASILDO, GUTIÉRREZ y RUIZ, op. cit., 2005. 
el acceso a los mismos, el tipo de suelos que predomina en aquellas áreas más próximas y accesibles a esos centros, la inserción de estos en las vías de comunicación y el posible reflejo de ello ya no sólo en conexión con su emplazamiento, sino también con su cultura material y con el propio desarrollo alcanzado por cada uno de ellos.

Así, el objetivo principal es, partiendo de aquellos criterios de tipo económico que caracterizarían el patrón de asentamiento de esos centros, aproximarnos a los rasgos básicos que definirían las actividades económicas en ambos territorios de estudio, así como a los aspectos que determinarían la explotación del territorio en época ibérica y las transformaciones que implicará, en este sentido, la instalación romana en el Sureste.

Al igual que apuntamos para los análisis referidos, de forma más concreta, a la decisión locacional de los yacimientos comarcales, también ahora encontramos diversos problemas y limitaciones que debemos tener presentes, siendo quizás los más destacados aquellos relativos a la conexión que podría establecerse entre los distintos sectores de hábitats analizados y el medio natural que pudo caracterizar el entorno de los mismos. El propio hecho de que este último se trate de un espacio en continua transformación, nos impide conocer con precisión los rasgos que definirían el medio en los periodos de estudio y cual sería, realmente, el carácter de esas tierras en las que vemos instalados muchos de los asentamientos comarcales, así como el de los territorios de su entorno más inmediato. Así, por ejemplo, en el Noroeste murciano se advierten importantes cambios ya desde los momentos finales del siglo XVIII, con la desaparición de amplias zonas forestales y de pastos, siendo así fundamentales los datos que nos aportan muchas de las fuentes anteriormente señaladas.

Del mismo modo, también el uso de cartografías actuales supone un importante límite a la hora de analizar determinados sectores comarcales, quizás ampliamente transformados en las últimas centurias, al igual que también la tecnología utilizada en cada periodo de estudio condicionará, enormemente, la propia explotación de esos recursos y tierras y, en última instancia el rendimiento de los cultivos ${ }^{41}$.

Aun así, y al margen de las distintas limitaciones indicadas, consideramos que, a partir de los datos de los que disponemos, es posible, al menos, llevar a cabo una primera aproximación a muchas de esas cuestiones planteadas, y, en definitiva, a las bases económicas que encierra el patrón de asentamiento que reflejan los distintos centros comarcales.

Desde este punto de vista, varios son los análisis a tener presentes en conexión con los diversos aspectos indicados, algunos, además, en clara relación con los ya

41 VICENT, op. cit., 1991, pp. 99-108. 
apuntados en el apartado anterior. Entre ellos sería especialmente interesante atender a aquellos relacionados con la accesibilidad a las tierras del entorno por parte de los habitantes de esos yacimientos y a la viabilidad y la circulación por estos territorios en época ibérica y romana, cuestiones ambas, básicas, para comprender el patrón de asentamiento de esos centros y para lograr una visión más completa del mismo.

\section{a.) Análisis de accesibilidad a los recursos y tierras del entorno.}

Por lo que respecta a este primer análisis, el objetivo fundamental es el conocimiento del posible acceso que, desde esos asentamientos, pudo tenerse a las tierras del entorno y, especialmente, a aquellos sectores comarcales en los que vemos centrarse los recursos que pudieron interesar a una sociedad agropecuaria como la que caracteriza, al mundo ibérico del Sureste. Partimos por tanto de la idea de que el patrón de asentamiento de muchos de esos centros estaría, probablemente, en clara conexión con el potencial productivo de su entorno.

De este modo, y como punto de partida de nuestro análisis tomaremos aquellos aspectos relativos a la movilidad por el territorio, basándonos en el análisis de costes y, por tanto, en los condicionamientos que, para dicho desplazamiento, supone la propia orografía del terreno, quizás el rasgo más representativo, especialmente atendiendo al escaso conocimiento que tenemos del medio natural y de aspectos como la vegetación en estos momentos, siendo sin embargo conscientes, en todo momento, de que también otros factores pudieron limitar dicha movilidad.

De nuevo, los Sistemas de Información Geográfica, vuelven a presentarse como una herramienta eficaz para abordar este análisis, denominado, en la literatura anglosajona site catchment analysis ('análisis del área de captación económica'), y aplicado en los últimos años en diversos trabajos arqueológicos. La mayor parte de ellos toma, como distancia máxima a la que se pueden soportar los costes de desplazamiento y trabajo, propuesta por M. Chisholm para las comunidades campesinas europeas, y similar, además, a la que propone A. Ruiz para los oppida del Alto Guadalquivir $^{42}$, un radio de 3-5 kilómetros en torno a un determinado yacimiento. Más allá de dicha distancia, y superando las dos horas de camino, resulta 'antieconómico' andar, cultivar y volver al poblado en el mismo día ${ }^{43}$.

A pesar de ello, debemos ser conscientes de que, en el entorno de un determinado asentamiento y, en concreto, en esos 5 kilómetros de radio, podemos encontrar numerosos obstáculos que dificultarían dicho recorrido. De este modo, es fundamental

42 RUIZ, A. «Ciudad y territorio en el poblamiento ibérico del Alto Guadalquivir», en Los asentamientos ibéricos ante la romanización (27-28 febrero 1986). Madrid, 1987, pp. 9-2.

43 CAMBI y TERRENATO, op. cit., 2004, pp. 235. 
tener presente, e incorporar a dicho análisis, los propios rasgos que definirían la morfología de ese territorio, calculando el área de captación de recursos en base a límites espaciales y temporales. Así, sólo desde un punto de vista teórico, y con la condición esencial de que estemos ante un terreno totalmente llano, podríamos afirmar que esos 5 kilómetros corresponderían sólo a una isocrona de una hora de recorrido desde el punto de partida, en este caso el yacimiento, hecho que, en la mayor parte de los casos, aparecerá ampliamente condicionado por las pendientes del entorno de dichos centros, que dificultarán el desplazamiento por el terreno, reduciendo ese radio a distancias muy diversas en cada caso ${ }^{44}$. Aun así, no podemos olvidar que se trata, en todo caso, de áreas teóricas, que englobarían, sólo hipotéticamente, aquellos territorios de más fácil acceso para los habitantes de dichos centros y en los que pudieron desarrollarse las actividades económicas que constituirían la base fundamental para la supervivencia de los mismos.

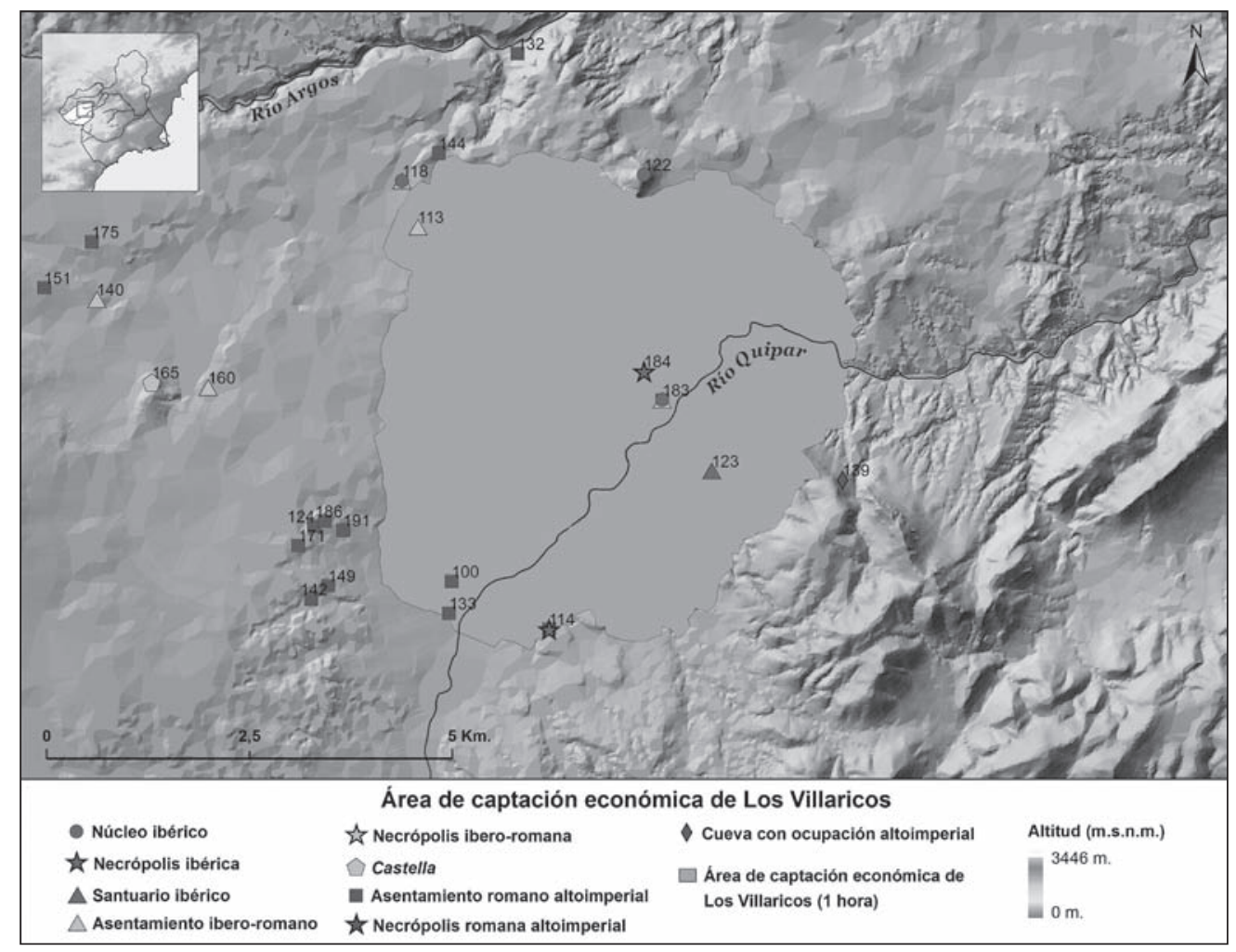

Figura 2. Área de captación económica del oppidum de Los Villaricos.

44 HIGGS y VITA-FINZI, op. cit., 1972, pp. 27. 
De este modo, el cálculo de dichos costes en un área determinada, constituye un aspecto más en el que los Sistemas de Información Geográfica ofrecen una amplia utilidad. En este sentido, a partir del ya mencionado modelo digital del terreno, es posible generar un mapa de pendientes y, a partir de él, calcular en base al mismo el desplazamiento por dicho territorio, tomando aquellos sectores con pendientes superiores al 20\% como áreas en las que el acceso debió quedar especialmente limitado, resultando la circulación por las mismas impracticable ${ }^{45}$.

Una vez calculada dicha accesibilidad es posible, por tanto, aproximarnos a los recursos que, probablemente, quedarían más próximos o a los que los distintos yacimientos tendrían un acceso más fácil, así como al posible solapamiento de aquellas áreas de captación de algunos de ellos, pudiendo de este modo analizar, además, la posible competencia entre centros a la hora de la explotación económica de estas tierras, o la propia potencialidad defensiva de determinados yacimientos, a los que el acceso sería especialmente complicado ${ }^{46}$.

b.) Análisis de viabilidad y de desplazamiento por el territorio: el trazado de rutas óptimas.

También los posibles ejes de circulación por estas tierras resultan fundamentales para comprender el patrón de asentamiento y el propio desarrollo económico de determinados centros, especialmente si tenemos presente el importante papel que los intercambios jugarían en la decisión locacional y la consolidación de muchos de los grandes núcleos ibéricos del sur y del Sureste peninsular.

Los Sistemas de Información Geográfica permiten, en este sentido, no sólo analizar los datos recopilados, sino, además, integrar todos ellos en dicho análisis. Así, por ejemplo, y junto a los propios yacimientos comarcales, aspectos como la presencia de miliarios, restos de rodadas o los propios ejes definidos por las vías pecuarias tradicionales, serían fundamentales en un análisis de este tipo ${ }^{47}$. Del mismo modo, el análisis particular de determinados elementos, como las importaciones áticas e itálicas, con anterioridad al cambio de Era, puede resultar también indicativo en este sentido.

Junto a todo ello, los SIG ofrecen además la posibilidad de advertir, en función de esos mapas de pendientes, aquellos sectores por los que dicho tránsito sería más sen-

45 CRIADO, op. cit., 1999; MAYORAL, op. cit., 2004; GRAU, op. cit., 2002.

46 FÁBREGA, op. cit., 2004, pp. 16-18 y 42-45.

47 ALFARO, C. «Vías pecuarias y romanización en la Península Ibérica», en Los rebaños de Gerión. Pastores y trashumancia en Iberia antigua y medieval. Seminario celebrado en la Casa de Velázquez, (15-16 enero de 1996). Collection de la Casa de Velázquez vol. 73. Madrid, 2001, pp. 218; FAIRÉN, S. et al. 'Las vías pecuarias como elementos arqueológicos», en GRAU MIRA, I. (Ed.): La aplicación de los SIG en la arqueología del paisaje. Alicante, 2006, pp. 51-56. 
cillo, así como generar 'caminos óptimos' entre los distintos yacimientos comarcales, es decir, itinerarios fáciles de transitar por los que, quizás, pudo discurrir el trazado de los ejes viarios en cada momento de estudio, y que, incluso, podemos comparar con esas rutas tradicionales e históricas que nos aportan las fuentes ${ }^{48}$, y con las que parecen definirse en base a la dispersión de esos determinados datos arqueológicos, como las citadas importaciones.

Este tipo de análisis no deja de presentar, sin embargo, al igual que los ya indicados, ciertos límites, como es el propio hecho de que no se tienen presentes determinadas variables, tales como la propia vegetación del terreno, las condiciones del suelo o aspectos, incluso, de tipo cultural, que también pudieron condicionar, en cierta medida, y junto a la orografía, la circulación por estos territorios ${ }^{49}$.

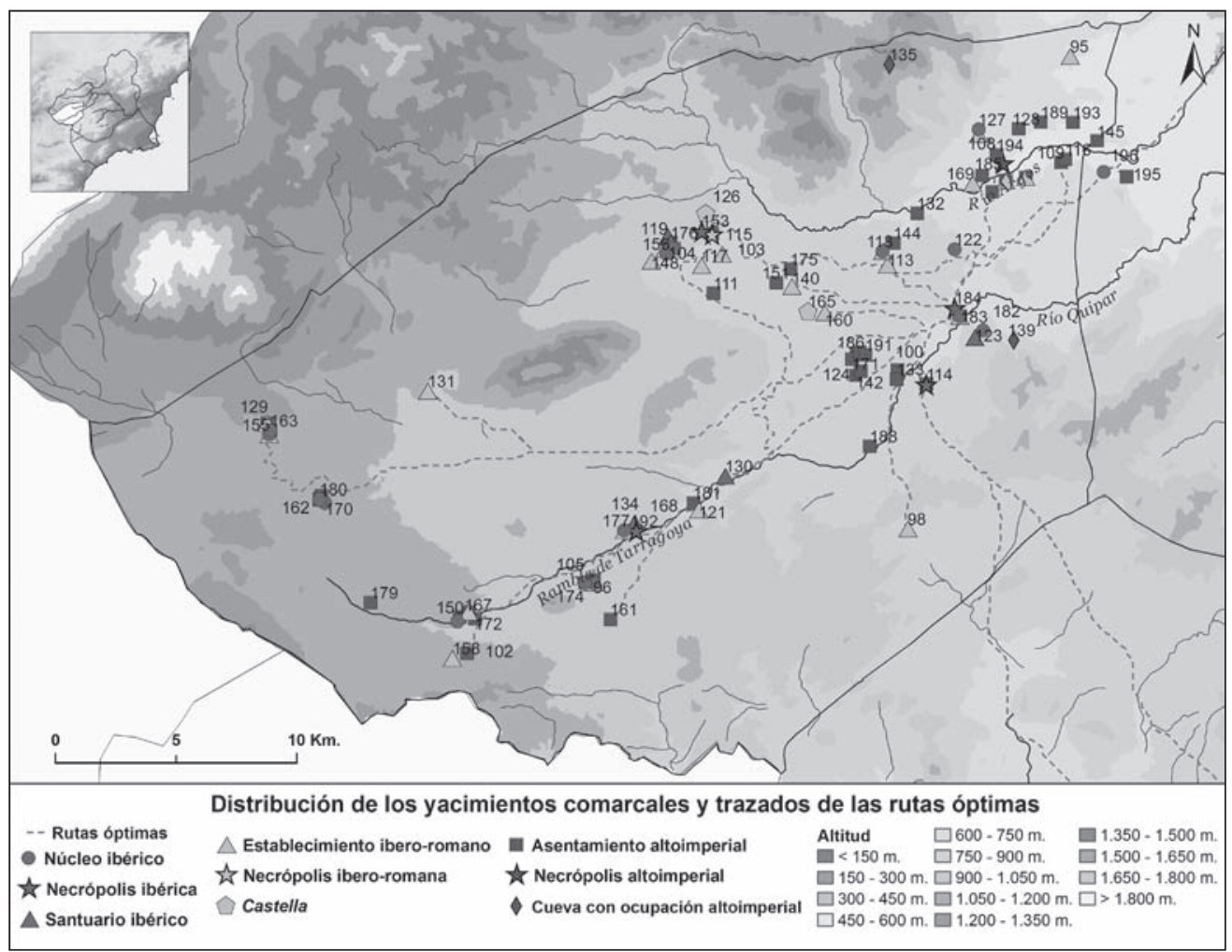

Figura 3. Trazado de rutas óptimas entre los principales yacimientos ibéricos y romanos del Noroeste regional.

48 BASILDO, GUTIÉRREZ y RUIZ, op. cit., 2005, pp. 133-168; CRIADO, op. cit., 1999.

49 HARVEY, op. cit., 1978; HAGGETT, op. cit., 1976. 
Del mismo modo, y si aceptamos el hecho de que no todos los núcleos documentados en ambas comarcas tendrían la misma entidad, también debemos tener muy presente el carácter principal o secundario de los mismos y el que pudieron tener esos posibles ejes viarios. Algunos de estos aspectos, además, se muestran aun más complejos si partimos de una visión diacrónica de dichos yacimientos, cuestión que también debemos tener muy en cuenta a la hora de valorar todos y cada uno de esos posibles trazados.

En general, y a través de este análisis, así como de los anteriores, será posible plantear aquellos criterios que definirían el interés de los yacimientos de cada periodo de estudio en las distintas comarcas, cuestión que completará, el tercer gran conjunto de análisis indicado, relativo, como señalamos, a los rasgos que el propio patrón de asentamiento de esos centros, refleja en relación a la organización y al control que pudo ejercerse de estos territorios en época ibérica y romana.

4.4.3. Analizando el control del territorio y el modelo de articulación del poblamiento en ambas comarcas

Los diversos análisis englobados en este último conjunto vendrían a completar los aspectos abordados por los indicados hasta ahora, completando así, la visión de aquellos criterios que definirían el patrón de asentamiento ibérico en estas tierras, ya no sólo a nivel económico, sino, atendiendo ahora, también, a aquellas cuestiones relativas a la articulación del poblamiento, al control y a la organización territorial de ambas comarcas en cada uno de los distintos momentos de estudio. Aspectos por tanto de tipo socio-político, estratégico o simbólico, como el posible papel que pudieron desempeñar determinados yacimientos, puntos de control y santuarios, serán los que entrarían ahora en juego junto a ese poblamiento. Estos representarían, además, tal vez, aquellos aspectos de mayor interés a la hora de aproximarnos a las transformaciones que supondrá la presencia itálica en este ámbito del Sureste peninsular y la integración de estas tierras en la órbita de Roma.

En general, serán muchos los datos a tener presentes a la hora de abordar el análisis de estas cuestiones en relación con ese patrón de asentamiento, incluidos aquellos que, sólo de forma indirecta, encuadrándolos en el contexto histórico y cultural en el que nos movemos, nos ofrecen información sobre los territorios de estudio. Así, quizás las propias defensas artificiales que muestran los oppida comarcales, o el propio santuario de La Encarnación, sean el más claro reflejo de la entidad de los mismos frente a otros núcleos documentados o de la sociedad que habitaría estos territorios en época ibérica, tal y como vimos en el caso de esas tierras andaluzas, del interior alicantino y del entorno de Edeta.

Son diversos los análisis que podrían ofrecen mayor información a la hora de 
abordar todos y cada uno de los distintos aspectos señalados, siendo, quizás, aquellos referidos al control territorial de dichos yacimientos, a las posibles jerarquías de asentamientos, así como a las áreas de influencia de los mismos, los que resultan de mayor interés y en los que los SIG vuelven a tomar un especial protagonismo.

\section{a.) Análisis de visibilidad e intervisibilidad.}

A lo largo del periodo ibérico, son diversos los elementos que, en general, pueden definirse como indicadores del control sobre un determinado territorio, siendo quizás, el mejor ejemplo, como apuntábamos, las propias murallas de un oppidum. El patrón de asentamiento vuelve a constituir así, también en este sentido, un aspecto básico a través del cual valorar estos aspectos.

El poder real, aparece así ejercido, en época ibérica, desde esos grandes núcleos de hábitat, lugares de residencia de la élite indígena y centros con capacidad suficiente para organizar social, política y económicamente un amplio territorio. Desde este punto de vista, dos cuestiones resultarían fundamentales a la hora de lograr el

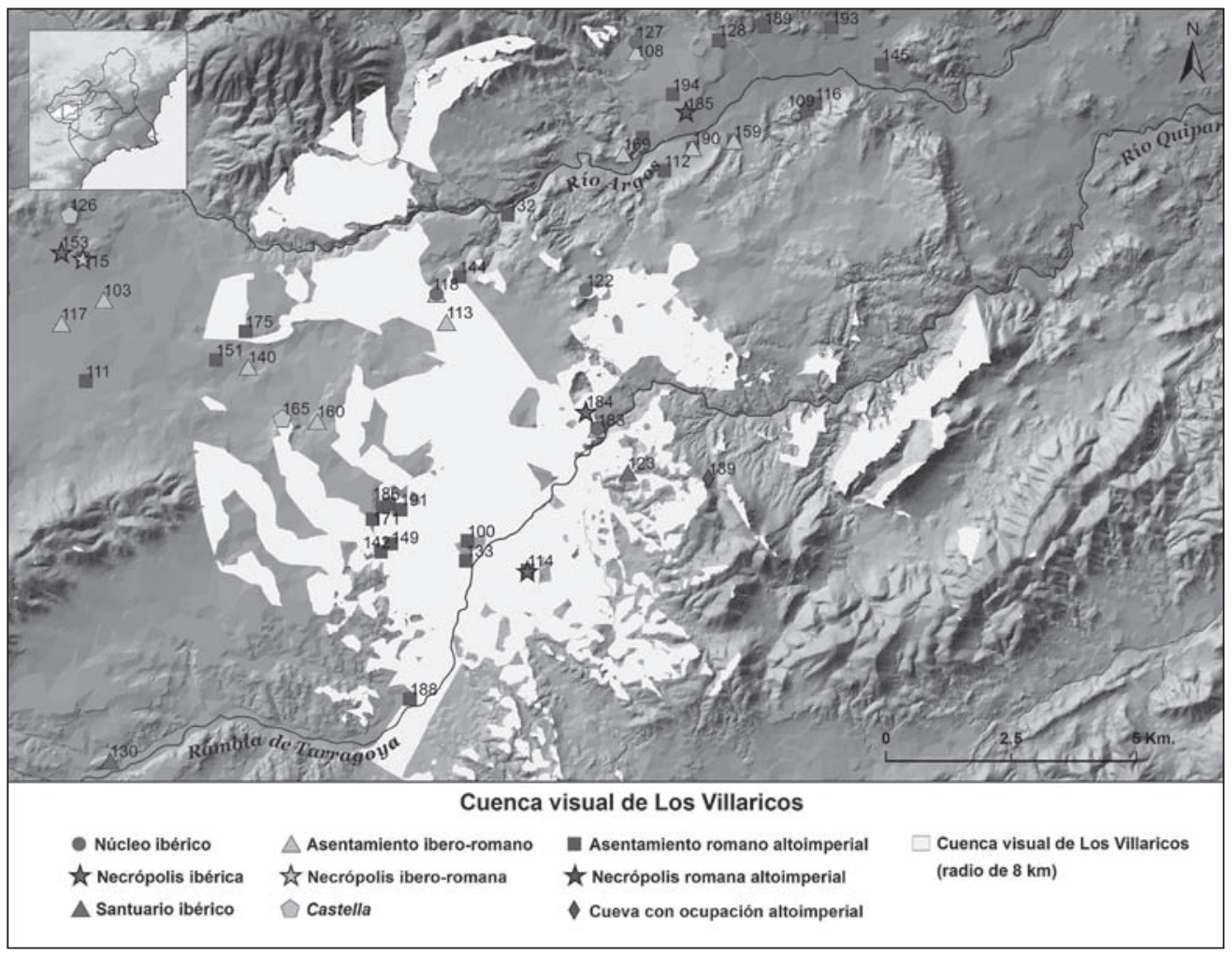

Figura 4. Cuenca visual del oppidum de Los Villaricos. 
control de dicho territorio: por una parte, la posibilidad de obtener un rápido y eficaz acceso al mismo, en clara relación con esas áreas de captación a las que ya nos hemos referido y, por otra, el control visual que dichos centros ejercerían sobre el mismo.

En este sentido, y si bien es cierto que no siempre podemos establecer una relación directa entre control visual y control real de un territorio, los trabajos que han abordado el análisis del mundo ibérico en diversos ámbitos peninsulares, parecen mostrar como, en el caso de un buen número de centros, sí es posible confirmar dicha conexión ${ }^{50}$, valorándose incluso más, en ocasiones, como elemento delimitador de territorios políticos, que el propio trazado de los Polígonos de Thiessen ${ }^{51}$. Dicho control, además, pudo ejercerse, bien de forma directa, desde un determinado asentamiento, como pudo ser ese oppidum, bien de forma indirecta, a través de otros núcleos secundarios en los que aquel pudo delegar dicha función, tal y como se ha apuntado para otros ámbitos del mundo ibérico ${ }^{52}$.

Desde esta perspectiva, el estudio de la visibilidad, se convertiría en un aspecto fundamental a la hora de aproximarnos a ese control del territorio y a la propia organización del mismo en cada uno de los distintos periodos abordados en nuestro trabajo. La orografía constituirá, de nuevo, el principal aspecto a tener en cuenta, sin olvidar los condicionantes que, quizás, pudieron representar también la propia vegetación o las circunstancias ambientales, cuestiones que, desgraciadamente, desconocemos, al no contar con estudios de tipo paleoambiental en ninguna de las dos comarcas. Del mismo modo, también otros aspectos, como el punto de observación elegido o la altura del observador, condicionarían esa visibilidad y debemos tenerlos muy presentes a la hora de llevar a cabo los análisis planteados, ajustando dichas variables de la forma más precisa en cada caso ${ }^{53}$.

Así, y partiendo de nuevo de ese modelo digital del terreno será posible calcular las cuencas visuales de los diversos yacimientos documentados en ambos territorios de estudio, que nos permitirán aproximarnos no sólo a la visibilidad de los mismos, incluida su orientación, sino también a las posibles relaciones visuales que podrían establecerse entre ellos y a la propia visibilización de determinados núcleos, como

50 WHEATLEY, D. y GILLINGS, M. Spatial Technology and Archaeology. The archaeological applications of GIS. Londres - Nueva York, 2002, pp. 201-205.

51 GRAU, op. cit., 2002, pp. 26.

52 MAYORAL, op. cit., 2004, pp. 150-151.

53 BERMUDEZ, MAYORAL y CHAPA, op. cit., 2006; BASILDO, GUTIÉRREZ y RUIZ, op. cit., 2005; RUIZ, A. y MOLINOS, M. «Elementos para un estudio del patrón de asentamiento en las campiñas del Alto Guadalquivir durante el horizonte ibérico pleno», Arqueología Espacial, 4. Coloquio sobre distribución y relaciones entre los asentamientos, 1984, pp. 187-206; GRAU, op. cit., 2002, pp. 26-27. 
esos oppida comarcales, en el territorio ${ }^{54}$. Del mismo modo, será posible advertir las posibles transformaciones que se observan en el control del territorio y las tendencias que definirían el mismo en cada uno de los distintos periodos de estudio, partiendo del análisis de conjunto de las cuencas visuales de todos esos yacimientos ${ }^{55}$.

\section{b.) Análisis de jerarquías de asentamientos.}

El estudio de las posibles jerarquías de yacimientos que se documentan en el territorio analizado es, quizás, uno de los aspectos que plantea una mayor complejidad, ya que, como indicábamos, la mayor parte de la documentación disponible corresponde a datos de superficie que no nos permiten aproximarnos a aspectos fundamentales en este sentido como la propia extensión de esos núcleos ${ }^{56}$. Aun así, otros muchos aspectos, como el propio patrón de asentamiento, pueden también ser tomados en consideración desde este punto de vista a la hora de abordar dicha cuestión en el marco del mundo ibérico del Sureste, apuntando, todos ellos, a una clara jerarquía de asentamientos en ambas comarcas de estudio, tal y como se ha podido advertir también en el ámbito edetano o en el interior alicantino.

En todo caso, también a la hora de abordar estos aspectos la información generada a través de esos análisis SIG resulta de gran interés, pudiendo así ponerla en conexión, además, con otros aspectos referidos a cuestiones de tipo simbólico, estratégico y cultural, así como a la que nos han ofrecido muchos de los análisis ya realizados y referidos a otros aspectos del patrón de asentamiento de estos centros, tales como aquellos relativos al control visual de los mismos o a su propia visibilización en las áreas de estudio ${ }^{57}$.

\section{c.) Análisis de territorialidades teóricas: los Polígonos de Thiessen.}

Como último aspecto a tomar en consideración en conexión con el estudio del patrón de asentamiento de época ibérica y, y tomando como base para aproximarnos a él las distintas cuestiones y análisis planteados hasta ahora, cabría señalar el estudio de las áreas de control o de influencia de aquellos centros que, en base a ese análisis de jerarquías de poblamiento, se hallarían, probablemente, a la cabeza de estos territorios.

54 CRIADO, F. «Visibilidad e interpretación del registro arqueológico», Trabajos de Prehistoria 50, 1993, pp. 45-51; CRIADO, op. cit., 1999, pp. 18-19; GRAU, op. cit., 2004, pp. 68-72; BASILDO, GUTIÉRREZ y RUIZ, op. cit., 2005, pp. 153.

55 WHEATLEY y GILLINGS, op. cit., 2002, pp. 207-208; LLOBERA, op. cit., 2006, pp. 150; BASILDO, GUTIÉRREZ y RUIZ, op. cit., 2005, pp. 163-164 y 168; FÁBREGA, op. cit., 2004; MARTÍN, BERMÚDEZ y PERLINES, op. cit., 2004; GRAU, op. cit., 2006, pp. 211-226.

56 SANTOS VELASCO, op. cit., 1994, pp. 20-22; BURILLO, F. El Valle Medio del Ebro en época ibérica. Constribución a su estudio en los ríos Huerva y Jiloca Medio. Zaragoza, 1980, pp. 440-441.

57 BASILDO, GUTIÉRREZ y RUIZ, op. cit., 2005, pp. 168; BURILLO, op. cit., 1980, pp. 263265 y 299-310; HAGGETT, op. cit., 1976. 
También los Sistemas de Información Geográfica ofrecen interesantes posibilidades de análisis en esta línea, que nos permitirán establecer, en base a los denominados 'Polígonos de Thiessen', las posibles áreas de influencia de los núcleos principales documentados en cada comarca de estudio. Dicho análisis trata de generar, partiendo de un conjunto disperso de puntos, en este caso, los distintos yacimientos documentados, una serie de polígonos irregulares que corresponderían a aquellas áreas que se situarían más próximas a cada uno de dichos puntos o yacimientos ${ }^{58}$.

El análisis se basa, así, en dos supuestos, que, sin embargo, resultan bastante discutibles, especialmente si tomamos en cuenta variables como la propia orografía o la entidad concreta de esos núcleos, entre otras muchas. Por un lado, acepta que el área situada dentro de los límites del polígono se encontraría más cerca del yacimiento que de cualquier otro centro. Por otro, presupone que una población domina todo el área situada geométricamente más cerca de ella ${ }^{59}$.

Existen, asimismo, otros aspectos que limitan este análisis y que no nos permiten plantearlo sino como una simple aproximación teórica a esas posibles territorialidades. En este sentido, por ejemplo, no podemos olvidar, tampoco, el posible papel que, desde este punto de vista, pudieron jugar también los santuarios, y no únicamente esos núcleos de hábitat, tal y como se ha puesto de manifiesto en más de una ocasión en otras áreas ibéricas y del ámbito Mediterráneo ${ }^{60}$.

De este modo, y siendo conscientes de esas limitaciones, y de que se trata de un análisis ampliamente criticado en su aplicación de forma particular, consideramos que, quizás, puede resultar de mayor interés en combinación con otros de los ya realizados, y que aportaban información sobre el control visual, los ejes de comunicación o la propia dispersión del poblamiento ibérico ${ }^{61}$, tal y como ha demostrado su aplicación en estudios llevados a cabo en otros ámbitos peninsulares y del Mediterrá-

58 HODDER y ORTON, op. cit., 1999, pp. 71-72.

59 HAGGET, op. cit., 1976, pp. 320-321.

60 RUIZ, A. y MOLINOS, M. Iberos en Jaén. Jaén, 2007, pp. 111-120; CULTRARO «Dimore sacre e luoghi del tempo: Appunti per uno studio della percezione dello spazio sacro nella Sicilia dell'Antica Età del Bronzo», Papers in Italian Archaeology VI. Communities and settlements from the Neolithic to the Early Medieval Period. Proceedings of the 6 Conference of Italian Archaeology held at the University of Groningen, Groningen Institute of Archaeology, The Netherlands, April 15-17, 2003. Volume I, BAR International Series 1452 (II), 2005, pp. 588-591; ZIFFERERO «La geografia del sacro nelle società complesse: ipotesi per una ricerca sull'Italia medio-tirrenica preromana», en MOLINOS, M. y ZIFFERERO, A. (a cura di): Primi popoli d'Europa. Proponte e riflessioni sulle origini della civiltà nell'Europa mediterranea. Atti delle Riunioni di Palermo (14-16 ottobre 1994) e Baeza (Jaén) (18-20 dicembre 1995). Firenze, 2002, pp. 146; CARDETE, M.C. «La polis como articulación social: el caso arcadio», Gerion 23, n 1, 2005, pp. 94.

61 RUIZ, A. y MOLINOS, M. Los iberos. Análisis arqueológico de un proceso histórico. Barcelona, 1993, pp. 122-123; MAYORAL, op. cit., 2004, pp. 130-140; HODDER y ORTON, op. cit., 1999, pp. 71-72. 


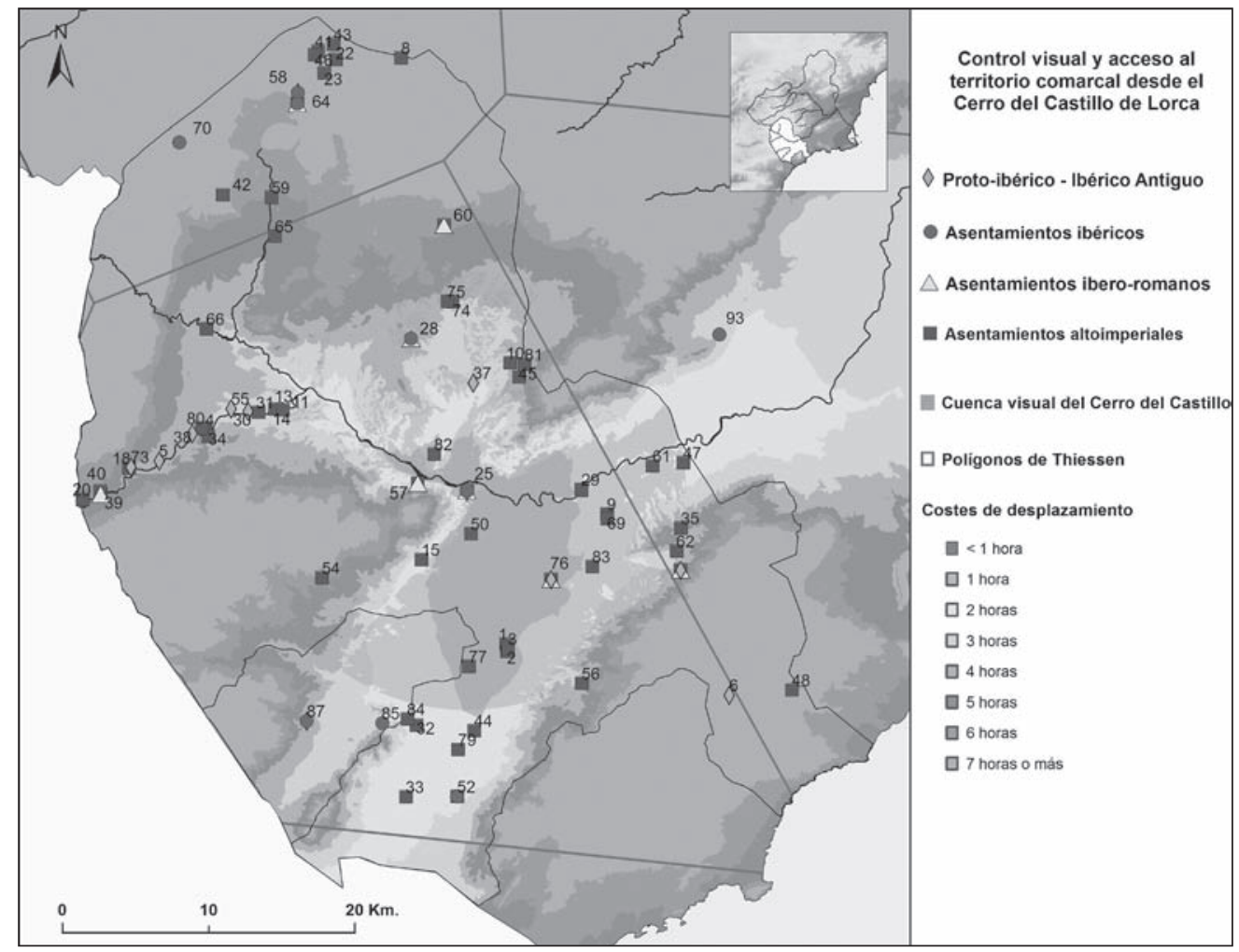

Figura 5. Combinación del análisis de Polígonos de Thiessen con otros análisis SIG aplicados al Cerro del Castillo de Lorca.

neo prerromano ${ }^{62}$. Desde esta perspectiva, dichos polígonos, no constituirán sino un elemento más para intentar aproximarnos, partiendo del análisis de ese poblamiento, a la posible organización territorial ibérica en ambas comarcas y a su desintegración con la instalación de Roma en estas tierras. Aun así, consideramos interesante atender

62 RUIZ y MOLINOS, op. cit., 1993, pp. 122-123; RUIZ y SANMARTÍ, op. cit., 2003, pp. 40-43 y 48; BAENA y BLASCO, op. cit., 1997, pp. 214-216; MAYORAL, op. cit., 2004, pp. 130-140; D'ERCOLE, V., DI GENNARO, F. y GUIDI, A. Valore e limiti dei dati archeologici nella definizione delle linee di sviluppo delle comunità protostoriche dell'Italia centrale», en MOLINOS, M. y ZIFFERERO, A. (a cura di): Primi popoli d'Europa. Proponte e riflessioni sulle origini della civiltà nell'Europa mediterranea. Atti delle Riunioni di Palermo (14-16 ottobre 1994) e Baeza (Jaén) (18-20 dicembre 1995). Firenze, 2002, pp. 114-115; RAJALLA, U. «From a settlement to an early state? The role of Nepi in the local and regional settlement patterns of the Faliscan area and inner Etruria during the Iron Age», en ATTEMA, P., et al. (Ed.): Papers in Italian Archaeology VI. Communities and settlements from the Neolithic to the Early Medieval Period. Proceedings of the 6 Conference of Italian Archaeology held at the University of Groningen, Groningen Institute of Archaeology, The Netherlands, April 15-17, 2003 Volume I, BAR International Series 1452 (II). Oxford, 2005, pp. 708-710. 
a esta cuestión que ha ofrecido interesantes datos en otras áreas peninsulares y que, además, enlazaría con la visión de conjunto que pretendemos ofrecer de la evolución del patrón de asentamiento y la ocupación y explotación del territorio en estas tierras, y, en definitiva, de aquellos rasgos que definirían el poblamiento ibérico regional así como los que marcarían su paulatina transformación con la llegada de Roma.

\section{Conclusiones}

En general, hemos pretendido presentar, a grandes rasgos, nuestra propuesta de trabajo, encuadrándola en el marco general de los estudios sobre el poblamiento ibérico que se están llevando a cabo en los últimos años en el ámbito peninsular, y centrándonos, especialmente, en el análisis de la metodología utilizada, que consideramos de mayor interés dentro del contexto en el que se inserta la línea de trabajo planteada.

Somos conscientes de la complejidad de abordar un estudio como el que proponemos, tanto por la amplia variedad de datos y conocimientos que deben entrar en juego en el mismo, como por la escasez de la información de la que disponemos, en muchas ocasiones. A pesar de ello, como hemos podido advertir, el estudio del poblamiento, de la ocupación del espacio y de la organización territorial, partiendo del análisis de ese patrón de asentamiento y de su transformación a lo largo de los siglos, resulta de gran interés para comprender, en su totalidad, el mundo ibérico regional y el proceso de integración del mismo en la órbita de Roma.

Sólo analizando de forma global, todos y cada uno de los aspectos planteados, y ayudados por el uso de los Sistemas de Información Geográfica, será posible ofrecer, por primera vez, una imagen amplia, diacrónica y comparativa de estos territorios en época ibérica, insertándolos, además, gracias al conocimiento que tenemos de esas otras áreas levantina y andaluza, en el contexto histórico y cultural del mundo ibérico del sur y del Sureste peninsular. 